\title{
Aproximación al asentamiento humano temprano en los oasis de San Pedro de Atacama ${ }^{1}$
}

Carolina Agüero P. ${ }^{2}$

\begin{abstract}
RESUMEN
Se presentan los resultados de una prospección sistemática de los oasis de San Pedro así como de su quebrada aledaña, la de Vilama. Esta constituye una aproximación preliminar al asentamiento humano temprano en la localidad, orientada a actualizar y darle contenido a la secuencia cronológica y cultural del Formativo local. El objetivo final es aclarar la naturaleza, causas y manifestaciones de dicho proceso dentro de un marco históricocultural optimizado. Los resultados obtenidos se discuten en relación a propuestas previas para finalmente sugerir la existencia de un sistema de asentamiento particular al ámbito de oasis.
\end{abstract}

Palabras claves: prospección - asentamiento - Período Formativo - San Pedro de Atacama.

\begin{abstract}
We give the results of an archaeological survey of the oases of San Pedro and the Vilama basin. This initial approach to early human settlement in the locality aims to update and give contents to the chronological and cultural sequence of the local Formative Period. Our final objective is to explain the nature, reasons and expressions of the said process within a thus enhanced historical and cultural framework. These results are discussed in connection to previous proposals, suggesting the existence of a particular settlement system for the oasis area.
\end{abstract}

Key words: survey - settlement - Formative Period - San Pedro de Atacama.

Recibido: marzo 2005. Aceptado: agosto 2005.

\section{Introducción}

La prolongada y densa ocupación que han tenido los oasis de San Pedro de Atacama es evidente en la enorme cantidad de sitios arqueológicos, los

1 Este artículo es resultado del Proyecto FONDECYT 1030931: "Registro arqueológico y cronología del Período Formativo en los oasis de San Pedro de Atacama".

2 Instituto de Investigaciones Arqueológicas y Museo R. P. Gustavo Le Paige s. j., Universidad Católica del Norte. Calle Gustavo Le Paige 380, San Pedro de Atacama, II Región, CHILE. Email: maguero@ucn.cl que, a pesar de los esfuerzos realizados por Le Paige (1957/58 en adelante) y por Llagostera y Costa (1999), a la fecha no han sido bien sistematizados. Por otra parte, la definición cronológica y cultural a lo largo de esta larga secuencia agroalfarera tampoco ha sido clara. Lo anterior es particularmente crítico para el lapso comprendido entre el $1000 \mathrm{AC}$ y el $400 \mathrm{DC}$, por cuanto la secuencia formativa de San Pedro ha sido formulada a partir de la arqueología funeraria, y se basa fundamentalmente en los contextos de Toconao Oriente, situados fuera de la localidad (Berenguer et al. 1986; Tarragó 1989). Por ello, sólo tres fechados que sustentan esta secuencia provienen de los oasis (Núñez 1976; Berenguer et al. 1986). Se suma a lo anterior, que la complementación con la secuencia habitacional y la obtención de fechas de asentamientos diversificados, no ha surgido de los oasis mismos ni de las quebradas cercanas, sino del sur del Salar. De este modo, desde Tulan se ha planteado la existencia hipotética de una primera fase agroalfarera para San Pedro de Atacama, llamada Tilocalar, al mismo tiempo que se ha proyectado la complementación habitacional para sus fases funerarias media y tardía, conocidas como Toconao y Sequitor (Tarragó 1989; Núñez 1992, 1994, 1995). Sin embargo, todavía no hay suficiente claridad ni investigación respecto al rol que cumplieron los oasis de Beter, Poconche y Cucuter como pioneros agrícolas que hacia el 380 AC eclosionan en la aldea de Tulor, cuyo notable desarrollo debió tener antecedentes en los mismos oasis y su entorno, pero todavía mínimamente conocidos.

Así, la proyección del modelo del "transecto Tulan" planteado por Núñez (1995) para el sur del Salar, donde se desarrolló un modo de vida pastoralista, ha servido para explicar el origen y desarrollo de las sociedades formativas en los oasis de San Pedro. Este autor señala que para comprender el tránsito hacia un manejo sedentario del territorio hay que tener en cuenta la larga historia previa de las sociedades arcaicas, en términos de su subsistencia y manejo del espacio. La caza y 
recolección y la domesticación de camélidos habría ocurrido a partir de prácticas arcaicas desde campamentos semipermanentes articulando distintos espacios productivos en una gradiente altitudinal. Esto habría propiciado ocupaciones formativas tempranas agropastoralistas, a partir de las cuales se construirían aldeas en las quebradas intermedias. Hacia el 400 AC éstas se abandonarían, emplazándose las primeras aldeas en los oasis bajos vinculadas al control del espacio agrícola, apoyado en la recolección de frutos arbóreos. Puesto que este modelo surge desde un ambiente apto para el desarrollo del pastoralismo, se debe alterar el esquema explicativo y tratar los datos desde el oasis, siendo probable que el inicio del uso agrícola de éstos haya sido apoyado por la recolección de algarrobo y chañar junto a la crianza de llamas mantenidas en las quebradas. En este sentido, este modelo debe ser puesto a prueba en los oasis de San Pedro para determinar quienes iniciaron allí este proceso, creemos que con una orientación recolectora y agrícola, más que pastoralista como sucedió al sur del Salar, integrando en ello, probablemente, a la quebrada de Vilama.

Por otra parte, los momentos post-Tilocalar están pobremente caracterizados en el oasis, desconociéndose los patrones habitacionales (salvo en Tulor), la relación de los sitios residenciales con los funerarios y una caracterización artefactual que considere a ambos tipos de yacimientos. Los contextos domésticos estudiados a la fecha no suman más de cuatro: Tulor-4 (Serracino 1976), Tulor-1 (Llagostera et al. 1984; Barón 1986), Coyo Aldea (Stovel 1997) y Calar (Llagostera 1988; Orellana 1988-89, 1990; ver también Le Paige 1957-58, 1964). Es decir, un sitio en la cuenca del Vilama y tres en los oasis de San Pedro.

En suma, vemos una serie de problemas de registro, contextos e integración de datos, que se deben a la carencia de investigaciones sistemáticas dirigidas a precisar los contenidos cronológicos y culturales de los distintos momentos del desarrollo formativo al interior de los oasis de San Pedro, lo que nos ha llevado a afinar y actualizar estos registros, para esclarecer la naturaleza, causas y manifestaciones de dicho proceso dentro de un marco histórico-cultural optimizado.

Un primer paso orientado a solucionar algunas de las falencias a que hemos hecho referencia, ha consistido en el estudio de las colecciones arqueológicas de San Pedro lo que nos permitió identificar evidencias de ocupaciones formativas tempranas dando los primeros indicios de un proceso adaptativo en términos de la intensificación de la ocupación de los oasis bajos (Agüero et al. 2004 Ms). Ese antecedente sustentó la realización de una prospección sistemática de los oasis bajos de San Pedro y de su quebrada aledaña, la de Vilama, como una primera aproximación al asentamiento humano en la localidad, orientada a actualizar y darle contenido a la secuencia cronológica y cultural del Formativo local. Son los resultados de este trabajo los que se ofrecen en esta oportunidad.

\section{Las áreas consideradas: Descripción y antecedentes}

La prospección incluyó dos áreas: la cuenca del río Vilama, y los oasis situados al sur de San Pedro de Atacama, en el margen norte del Salar (ver Figura 1, más adelante).

En la cuenca del Vilama, iniciamos la prospección al sur de Guatin, donde se unen los ríos Puritama y Puripica dando origen al río Vilama a $3250 \mathrm{~m} . \mathrm{snm}$, finalizándola en el Pucara de Vilama a 2588 m.snm. Bajando desde Guatin, el paisaje se caracteriza por lomas suaves y onduladas, seguidas por mesetas relativamente angostas que son cortadas por la caja del río, salvo en cinco sectores: Incapite, Cartuche, Ghatchi, Calar y Vilama en donde no hay farellones rocosos, siendo los lugares donde cruzan senderos y huellas caravaneras, y en los cuales se encuentran la mayoría de los sitios arqueológicos agroalfareros. En el curso medio, Calar constituye el lugar en el cual el valle se abre aprovechándose para construir numerosas estancias en tiempos subactuales, utilizando el río para el riego de melgas y crianza de animales. Este paisaje continúa hasta que el río se vuelve a encajonar cerca del lugar que se eligió para construir el Pucara de Vilama. A unos cientos de metros antes de éste, una antigua huella caravanera cruza el río y se introduce a través de un abra a San Pedro de Atacama.

En el caso de los oasis bajos de San Pedro, la prospección consideró el área comprendida en los cuadrantes situados entre los vértices noroeste UTM 
$576000 \mathrm{E} / 7459000 \mathrm{~N}$ y sureste $579000 \mathrm{E} /$ 7458850 y los vértices noroeste $580000 \mathrm{E} /$ $7461000 \mathrm{~N}$ y sureste $586200 \mathrm{E} / 7458000$ entre los 2370 m.snm y 2395 m.snm, incluyendo los actuales ayllu de Cucuter, Poconche, Beter y sur de Tulor, puesto que los sectores ubicados al norte de ellos se encuentran ampliamente descritos en la literatura (Le Paige 1964, 1974a; Serracino 1976; Llagostera et al. 1984; Barón 1986). No obstante lo anterior, los sitios del período que nos interesa, situados al norte de estos ayllu (Tulor-4, Tulor-G, Tchecar, Sequitor Alambrado Acequia, Sequitor Alambrado Oriental, Yaye Corral de Toros, Coyo-12, Larache Acequia, Larache Callejón, Solor-3, Solor-6), fueron reconocidos e incluidos en la base de datos.

\section{1) La cuenca del Vilama}

Esta área incluye desde Guatin hasta el ayllu de Vilama, unos $5 \mathrm{~km}$ al norte de San Pedro de Atacama. El conjunto de esta cuenca es conocido en la literatura arqueológica como Ghatchi, o Lomas de Ghatchi, y Loma Negra. Le Paige (1964) señala que el nombre de Ghatchi, sintetiza una extensa zona de $28 \mathrm{~km}$ de largo y $4 \mathrm{~km}$ de ancho, ubicada al noreste de San Pedro de Atacama, comprendiendo desde Vilama hasta Guatin, con 32 lomas divididas por quebradas pequeñas. Por su parte, Loma Negra es un largo espinazo de basalto que baja desde el Sairecabur en dirección NE-SO y que alcanza unos $20 \mathrm{~km}$ de largo, corriendo desde Puripica hasta Ghatchi.

El asentamiento humano en esta zona se ha extendido por varios períodos. El área, que formó parte de la discusión del "pre proyectil point", fue recorrida por Le Paige en 1963, quien caminó la mayoría de las lomas descubriendo las "ruinas de Ghatchi" y muchos talleres del "Ghatchinense", así como canteras, y en las cumbres, varios amontonamientos de piedras. Aclara que Ghatchi I y II designa las épocas del Ghatchinense, y que Ghatchi seguido de 1 y 2, designa las ruinas de Ghatchi (Le Paige 1964: 13). La periodificación propuesta por Le Paige (1963, 1964) en base a los atributos morfológicos de los artefactos líticos, fue posteriormente complementada por Stehberg y Serracino (1974) con el estudio de los amontonamientos de piedra y estructuras características de Ghatchi.
Le Paige excava al pie de los muros en Ghatchi2 y recolecta 3139 líticos (1964: 15). Menciona dos sectores, uno al norte de la meseta, sin cerámica, y otro al sur en el que solo "aparecen unos pedacitos en la superficie, pero, hasta hoy, ninguno en profundidad" (Le Paige 1963a: 11), describiendo a este asentamiento como un "sitio demostrativo de la supervivencia de la vida humana hasta el Mesolítico" (Le Paige 1964: 14). Con ello, Le Paige propone que Ghatchi-1 y Ghatchi-2 representarían un período transicional entre el Arcaico Tardío y el Formativo Temprano.

En la meseta de Calar excava una cueva encontrando alfarería negra pulida y desechos de talla "de la confección de los instrumentos de principios de la agricultura (azadones, palas)" (1963: 184). Posteriormente excava 20 tumbas en la aldea de Calar, donde después trabajan Orellana (1988-89, 1990) y Llagostera (1988) reconociendo tres estratos culturales, caracterizándose el inferior por contener "alfarería temprana, arterfactos microlíticos" instrumentos de obsidiana, de agricultura y huesos de camélido, entre otros. Comprueban la existencia de hoyos de postes y pozosbodegas que contenían restos carbonizados de madera, por lo que afirman que las "relaciones con Tulor son claras". De Calar se conoce tan

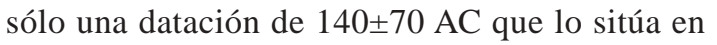
el Formativo Medio (Orellana 1988-89; Llagostera 1988), aunque es probable que sea aún más temprano, estimándose su auge cercano a los 200 AC. Según Orellana (1990: 24) Calar debió contar en su momento de mayor concentración demográfica con cerca de 150 habitantes. Se trataría de un conjunto habitacional en el que identifica cerca de "34 estructuras situadas en semicírculo, alrededor de un gran espacio libre que luego fue amurallado y dividido en dos sectores". La aldea se emplaza en la primera terraza y en el descenso hacia el río existiría una terraza agrícola, vinculada a la presencia de palas líticas en el asentamiento.

En síntesis, los antecedentes recopilados de la cuenca del Vilama hacen principalmente referencia a sitios arcaicos y, formativos, al mismo tiempo que sugieren una significativa ocupación humana en ambos momentos. 
2) Los oasis bajos de San Pedro de Atacama

Para los oasis bajos constituidos por los actuales ayllu de Cucuter, Poconche, Beter y Tulor, la atención no ha sido la misma que para el área anteriormente reseñada. Con excepción de Tulor (Le Paige 1964, 1974a; Serracino 1976; Llagostera et al. 1984; Barón 1986) y Beter (Le Paige 1964, 1974), Cucuter y Poconche prácticamente han permanecido al margen de la investigación.

Muy distinta es la situación respecto de los ayllu de Catarpe, Quitor, Coyo, Sequitor, Solor y parte de Beter, situados al norte de la coordenada UTM $7461000 \mathrm{~N}$, en los que Le Paige realizó un intenso trabajo (Le Paige 1957-58, 1964, 1974, 1974a) al igual que otros autores (Llagostera et al. 1984; Barón 1986; Serracino 1986) en los sitios formativos habitacionales Tulor-1, Tulor-4, TulorG, y funerarios, Tchecar, Sequitor Alambrado Occidental (Acequia), Sequitor Alambrado Oriental (también poblado) ${ }^{3}$, Larache Acequia, Larache Callejón, Solor-3, Solor-6. Otros sitios formativos considerados en esta investigación emplazados fuera del sector prospectado, es decir, más al norte, son los asentamientos Coyo-12 (Llagostera y Costa 1999) y Yaye Corral de Toros (Hermosilla et al. 2003 Ms). En el área considerada en este trabajo, solo existen referencias por parte de Le Paige a tres sitios: Poconche (02-Po-12), Cucuter (no identificado) y Tchaputchayna (02-Be-16).

Poconche es señalado por Le Paige (1957-58, 1964) como uno de los cementerios más pobres de los oasis, del cual rescató cuatro tumbas con cerámica descrita como rústica, hecha en rodetes con gruesos granos de piedras negras, además de cuentas de malaquita y puntas de proyectil gruesas con "formas raras: la almendrada, la triangular con base escotada y recta" (1957-58: 66). Por su parte, Cucuter "no tiene nada más que pedazos

3 Le Paige (1974: 102) indica que a unos $130 \mathrm{~m}$ al sureste del cementerio encontró un sitio habitacional, pues ve morteros, manos para moler y fragmentos de cerámica: "Entre los últimos hay varios tipos primitivos anteriores al rojo pulido, siendo fechado por C14 en Argentina alrededor del 800 AC, perteneciente a la Cultura San Francisco". De acuerdo a esta descripción este sector correspondería al sitio 02-Po-25 que podría formar la parte norte del sitio Poconche de Le Paige (1964) (02-Po-12). Actualmente, ambos sitios se encuentran separados por una duna. de alfarería común y puntas de flecha pequeñas", aunque en todos estos oasis se encontraron tembetás (Le Paige 1957-58: 67).

Tchaputchayna constituye un asentamiento extenso con tres sectores de ocupación (Le Paige 1964, 1974): un cementerio al sur, muy deteriorado por las crecidas del río San Pedro y al parecer de dos épocas, con 67 entierros en pozos de forma irregular, en urnas o con urnas al lado (al igual que en Poconche), cerámica sin decorar y de aquella conocida como Mizque en Cochabamba, también San Pedro Negra Pulida y Coyo. En superficie cerámica "primitiva", otra "con granitos blancos, ungulada, como hechas por uñas de perro (...)" y otra modelada. Un segundo sector central está formado por 30 túmulos con morteros y manos de moler, hachas y azadones, martillos, urnas, pero sólo dos entierros. En superficie hay una gran variedad de alfarería Negra Pulida, Coyo, "casi pulida primitiva", "con granitos blancos, rosada con granitos blancos, ungulada", pipas, material lítico temprano y del "Neolítico", perforadores de cuarzo, lascas de obsidiana y tembetás, además de objetos de cobre, conchas marinas y caracoles de agua dulce. El tercer sector al norte, lo constituyen campos de cultivo. Esta descripción señala un amplio uso temporal del asentamiento. Muchos cuerpos del cementerio se encuentran "en cuclillas acostados de lado", como en Calar. Señala que no encontró ningún tipo de estructura, sin embargo, lo más probable es que los túmulos hayan constituido viviendas de material perecedero.

Posteriormente, Llagostera y Costa (1999) realizan una prospección sistemática orientada al registro de sitios habitacionales -la primera en la arqueología de San Pedro de Atacama- y a su puesta en secuencia de acuerdo a un análisis cerámico. Sin embargo, inexplicablemente la prospección dejó fuera a los oasis de Cucuter y Poconche. Esta omisión -seguramente motivada por el juicio de Le Paige (1957-58) respecto a su "pobreza" arqueológica-, los lleva a afirmar que las evidencias iniciales de ocupación humana se manifiestan preferentemente en Tulor (1999: 175), y que "antes de la Fase II los asentamientos se ubican preferentemente en el borde de la puna y en las quebradas, con grupos propiamente pastores..." refiriéndose a Tulan y Tilocalar (Llagostera y Costa 1999: 196). 
Antes, Llagostera y colaboradores (1984) ya habían excavado Tulor-1, aportando fechas radiocarbónicas que ubicaron la ocupación a comienzos de la era. Sugieren que en un primer momento pudo existir un sistema de asentamiento disperso, conformado por los sitios de los alrededores (p.e., Tulor-4) y que posteriormente Tulor-1 logró la consolidación aldeana a través de un crecimiento más intenso que el resto. Esto, debido a la necesidad de un núcleo que organizara las relaciones interregionales cada vez más complejas. En 1999, Llagostera y Costa registran en el sector 19 sitios arqueológicos, seis de los cuales no son estructurados, y la mayoría con seguridad conforma el conjunto de los sitios que circundan Tulor-1, y a Tulor Algarrobo (Le Paige 1964). En Beter, registran ocho sitios habitacionales, no obstante, la ausencia de coordenadas geográficas o UTM, nos impide relacionarlos con los sitios registrados por nosotros. Tratan de manera separada a Tchaputchayna (02-Be-16), donde registran cinco sitios, que parecen corresponder al asentamiento y al cementerio descrito por Le Paige.

Resumiendo, en los oasis bajos hay un gran desconocimiento de la existencia de sitios arqueológicos de todos los períodos, habiendo registro sistemático únicamente en parte de Beter y Tulor aunque no con criterios claros que permitan su identificación. Para Poconche y Cucuter sólo se cuenta con menciones imprecisas que sugieren un potencial registro de sitios tempranos.

\section{Metodología}

La cuenca del Vilama fue recorrida de norte a sur siguiendo la topografía del terreno. En cada margen del río se revisaron los sectores desde la cumbre del primer cordón de cerros cercano al mismo, hasta el sector más cercano a su lecho, abarcando hasta $800 \mathrm{~m}$ en línea recta desde el río al interior. Por otra parte, el área correspondiente a los oasis bajos de San Pedro fue recorrida en transectas este-oeste distanciadas $50 \mathrm{~m}$ entre sí.

\section{Registro de sitios arqueológicos}

Para el registro de sitios arqueológicos se utilizó una ficha que consideró la siguiente información: a) $\mathrm{N}^{\mathrm{o}}$ y nombre de sitio, donde la siglas indican la región, luego el ayllu o quebrada, y finalmente el número correlativo de sitio arqueológico; b) Coordenadas UTM, utilizando el Datum PSAD 56; c) Altitud (ídem); d) Tipo de sitio; e) Descripción; f) Dimensiones aproximadas; g) Cronología; h) Referencias publicadas, e, i) Observaciones y fotografías (sitio, emplazamiento, indicadores).

Respecto de los puntos (d) Tipo de sitio y (g) Cronología, se utilizaron las siguientes categorías y criterios adaptados de Núñez y Agüero (2003 Ms):

\section{Categorías de sitios arqueológicos}

1) Asentamiento estructurado ${ }^{4}$ : Conjunto de evidencias arquitectónicas que indican distintos grados de ocupación y permanencia territorial de mayor a menor complejidad.

1.1) Complejo: Evidencias de rasgos constructivos y ocupacionales concentrados, con presencia referencial en el paisaje y de relevancia patrimonial y monumental.

1.2) Discreto: Evidencias concentradas de menor valor constructivo, demográfico y patrimonial (conjunto de varias estructuras).

1.3) Disperso: Evidencias de recintos dispersos que eventualmente serían parte de un mismo asentamiento con valores discretos.

1.4) Estancia: Conjunto de recintos residenciales, corrales y de servicios dedicados a las actividades pastoralistas, de uso a veces estacional, construidas por pastores desde el Intermedio Tardío en adelante.

1a) Asentamiento no estructurado: Conjunto de evidencias (rasgos, líticos, cerámica) que indican distintos grados de ocupación y permanencia territorial de mayor a menor complejidad.

1a.1) Discreto: Evidencias concentradas de menor valor numérico, demográfico y patrimonial.

1a.2) Disperso: Evidencias que eventualmente serían parte de un mismo asentamiento con valores discretos.

2) Taller: Concentración de restos de talla lítica con presencia de materia prima, artefactos inconclusos y terminados, incluyendo residuos de lascas y esquirlas derivadas de las técnicas de percusión y presión. También incluimos aquí canteras-taller y eventos de talla.

\footnotetext{
4 Tomamos este criterio de Llagostera y Costa (1999: 179)
} 
3) Estructura: Recinto aislado con técnicas de pircado asociado a actividades más bien efímeras con distintas funciones.

3.1) Paradero ocasional: Estación pircada de protección con funciones no determinadas.

3.2) Abrigo bajo roca con o sin protección pircada: Ocupación en abrigos y cuevas.

3.3) Marca: Acumulación de rocas con fines de demarcación como hitos de propiedad u otras funciones.

3.4) Fundición: Evidencias de escoria, leña, carbón y mineral de cobre, generalmente en laderas de montículos.

4) Ceremonial: Estructuras de uso no doméstico vinculadas con actividades ceremoniales de distinta naturaleza.

4.1) Apachetas: Acumulamiento cónico de piedras arrojadas por caravaneros, constituyendo un ritual típicamente andino.

4.2) Mochadero: Lugar con concentración de mineral de cobre molido y quiebra de cerámica a modo de rituales de caravaneros y otras ocupaciones transitorias.

4.3) Huaqui: Quiebra ritual de cerámica, de carácter discreto.

4.4) Cementerio: Lugar en el cual se han depositado los muertos.

5) Arte rupestre: pictografías o grabados sobre un soporte rocoso.

6) Vía de circulación: sendero, camino o huella caravanera.

7) Registro aislado: Hallazgo de objetos arqueológicos aislados sin formar parte de un contexto cultural específico.

\section{Criterios para la determinación cronológica}

1) Cronología indeterminada: No existen evidencias para sostener una asignación temporal.

2) Prehispánico: Las evidencias solo sostienen que el sitio es anterior al contacto europeo.

3) Arcaico: Las evidencias corresponden a ocupaciones de cazadores recolectores anteriores a los períodos agrícolas y pastoralistas (9000-1300 AC). 4) Formativo: Las evidencias corresponden a ocupaciones agropastoralistas portadoras de cerámica situadas entre 1300 AC-500 DC.

5) Formativo Temprano: Las evidencias corresponden a ocupaciones agropastoralistas situadas entre $1300 \mathrm{AC}-350 \mathrm{AC}$.
6) Formativo Medio: Las evidencias corresponden a ocupaciones agropastoralistas situadas entre $350 \mathrm{AC}-100 \mathrm{DC}$.

7) Formativo Tardío: Las evidencias corresponden a ocupaciones agropastoralistas situadas entre 100 DC-500 DC.

8) Medio: Las evidencias corresponden a ocupaciones que muestran expresiones materiales locales o foráneas vinculadas con Tiwanaku (500-900 DC).

9) Intermedio Tardío: Las evidencias corresponden a ocupaciones tardías con ausencia de expresiones materiales relacionadas a Tiwanaku o al dominio incaico (900-1450 DC).

10) Tardío: Las evidencias corresponden a ocupaciones que exhiben expresiones materiales locales o foráneas relacionadas al dominio incaico (1450-1500 DC).

11) Histórico colonial hispánico y/o republicano (1500 DC en adelante): Las evidencias indican su filiación a ocupaciones ocurridas en momentos posteriores al contacto europeo.

12) Histórico etnográfico (1500 DC en adelante): Las evidencias son de tiempo histórico, pero se relacionan más directamente con ocupaciones indígenas.

Con posterioridad, la información de las fichas se sistematizó en una planilla EXCEL, luego de lo cual se seleccionó y aplicó el formato de cada columna (texto o numérico), guardándose el archivo en formato DBF (IV). El archivo obtenido se importó como tabla en el ArcView3.2a. Luego se agregó en el "View" la base de datos importada y la carta digital, quedando así la información disponible en cada punto.

Indicadores para la asignación cronológica y cultural de los sitios ${ }^{5}$

El estudio de colecciones de los sitios mencionados y que realizamos previamente, tuvo como fin sistematizar diferentes materialidades (cerámica, óseos, líticos) así como restos bioarqueológicos, arqueofaunísticos y paleobotánicos en indicadores, permitiéndonos establecer para el Período Formativo de San Pedro de Atacama, aunque de manera

Aún cuando se registraron sitios asignables a todos los momentos de la secuencia desde el Arcaico a tiempos históricos, aquí tratamos con el Formativo, por lo que los indicadores de este acápite están referidos a este período. 
preliminar, tres momentos (Agüero et al. 2004 $\mathrm{Ms}$ ), en cierto sentido coincidentes con las fases Tilocalar (componente inferior), Toconao y Sequitor. Un primer momento, transicional aún relacionado con prácticas derivadas del Arcaico, en el cual se inicia la ocupación del oasis en complementación con los ámbitos de quebrada, lo que se traduce en una gran movilidad, al que sigue una ocupación estable del oasis, la explotación de sus recursos y las primeras evidencias agrícolas (maíz) junto a interacciones extralocales que abarcan al Pacífico y al N.O.A., y finalmente, un momento tardío en el cual el proceso se consolida con un crecimiento poblacional promovido por la estabilidad económica, junto a una creciente complejidad social, integrándose los oasis a los circuitos caravaneros en los cuales el mineral de cobre tiene un papel importante. Con ello, reafirmamos la propuesta tradicional (Berenguer et al. 1986; Núñez 1994; Tarragó 1989), aunque otorgándole un mayor contenido y justificando la existencia de una fase formativa temprana en el oasis, hasta ahora inexistente o hipotética.

Durante los primeros momentos del Formativo ( $c a$. 1300-350 AC), destaca la presencia de cerámica del tipo Loa Café Alisado (LCA) junto a Los Morros $(\mathrm{LMS})^{6}$, y la utilización de gramíneas, indicando la obtención de recursos de quebradas. Se observa una continuidad arcaico-formativa en la industria de láminas y en la de instrumentos microlíticos, no obstante existir cambios como la aparición de instrumentos de molienda, distintos a los morteros de hueco cónico, como las conas, indicando actividades agrícolas incipientes o recolectoras de los bosques de algarrobo, aunque por el momento no se han registrado especies vegetales de oasis. Los perforadores y microperforadores, instrumentos indispensables para la fabricación de cuentas para collares, provenientes de tradiciones más tempranas, adquieren relevancia, y los instrumentos de uso cotidiano como cortantes y raspadores se hacen cada vez menos especializados y más expeditivos, demostrando distancia con las actividades de caza y faenamiento.

Hacia momentos medios (350 AC-100 DC), los instrumentos tallados se van especializando casi

6 Para acceder a las fechas de los tipos cerámicos a que hacemos mención, referirse a Uribe (2005, en prensa). exclusivamente en puntas de proyectil pequeñas y materias primas finas, dando paso a cuentas, pendientes y tembetás, o a artefactos de fuerte carga simbólica como hachas y mazos. Los perforadores siguen siendo un rubro importante y se agrandan y diversifican. También ya es clara la utilización del pelo de camélido en el hilado, y la actividad textil está presente en varios separadores de telar. Hay mayores indicios de agricultura y utilización de recursos locales como frutos de algarrobos y chañares, restos de Zea mays y conas, todo lo cual está avalado por los restos humanos que evidencian el consumo de granos y/o harinas sin cernir. Además, hubo gran cantidad de restos de maderas locales, siendo en Sequitor donde se utilizan más popularmente, y la especialización para el trabajo de materiales duros y blandos que continúa en el siguiente momento. El Strophocheilus oblongues, y varias clases de moluscos, indican intercambios y relaciones con otros territorios como el Pacífico y el N.O.A., tal cual lo anunciaba la mayor variabilidad de cerámicas alisadas, pulidas, gruesas y/o foráneas (LCA, Loa Rojo Alisado [LRA], Sequitor [SEQ], Toconao [TOC], LMS y Vaquerías [VAQ]; ver Uribe 2005, en prensa).

En tanto, en los contextos de la etapa tardía (100$500 \mathrm{DC}$ ) predominan los tipos pulidos, en particular SEQ, junto a alisados como LRA, y minoritariamente LCA y LMS, lo cual define un momento más cercano al Período Medio. Los martillos en granitos, andesitas y basaltos se tornan importantes. Aumentan los separadores de telar en Sequitor, relacionándose con un auge de las actividades textiles. Continúa el cultivo del maíz y la explotación de los recursos locales en complementación con otros de origen aún no definido como, por ejemplo, curcubitáceas, mejorándose la calidad nutricional. Resalta la proliferación de más categorías de Prosopis en un solo sitio, en concordancia con el auge de la industria especializada de las maderas que llega a constituirse en una de las más notables del oasis a partir de estos momentos al Período Medio en adelante, lo cual queda claramente expresado en el conjunto de objetos psicotrópicos de Toconao Oriente, Larache y Sequitor Alambrado Oriental. Se intensifica y se hace más diversa la producción de ornamentos en mineral de cobre y éste en sí mismo, acompañándose de líticos de carácter simbólico lo cual se relaciona con la producción de bienes ne- 
cesarios para la mantención de relaciones sociales, políticas y económicas, siendo de interés, en este último caso, haber encontrado las escasas evidencias de prácticas caravaneras únicamente en Solor3, lugar donde además abundan los objetos metálicos. El intercambio de bienes, y otros productos económicos, concuerda además con la presencia en Tchaputchayna de frutos carnosos, como las cucurbitáceas, de probable origen foráneo.

\section{Resultados}

La prospección permitió registrar un total de 253 sitios y 389 ocupaciones. En la cuenca del Vilama, de 160 sitios reconocidos por nosotros, con anterioridad sólo habían sido registrados $10(02-\mathrm{Vi}-$ 21, 02-Vi-67, 02-Vi-71, 02-Vi-75, 02-Vi-84, 02Vi-89, 02-Vi-100, 02-Vi-91，02-Vi-117，02-Vi160). En tanto en los oasis bajos, de 93 sitios registrados en esta investigación, sólo tres habían sido reconocidos previamente (02-Po-12, 02-Po25 y $02-\mathrm{Be}-16)$.
Además se reconocieron 11 sitios formativos que se emplazan fuera de las áreas consideradas, pero cuyas colecciones habíamos estudiado. Estos fueron Pelun en el ámbito de quebradas, y Tulor-1, Coyo-12, Larache, Larache Acequia, Sequitor Alambrado Oriental, Sequitor Alambrado Acequia, Solor-3 ( $3^{\text {er }}$ piso), Solor-6, Tulor-4 y Yaye Corral de Toros, en los oasis. Con ellos, en nuestra base de datos se ingresó un total de 264 sitios (Cuadro 1 y Tabla 1 al final).

A continuación realizaremos un análisis general de la cantidad, composición, categorías y emplazamiento de la totalidad de los sitios, para posteriormente ponerlos en secuencia y profundizar según las variables anteriores, en los tres momentos reconocidos para el Formativo. En los casos en que sea pertinente se comparará con la propuesta de patrones asentamiento, para el agroalfarero de los oasis, realizada por Llagostera y Costa (1999).

\begin{tabular}{|c|c|c|c|}
\hline Componente & Vilama & Oasis & Total \\
\hline Arcaico & 9 & 0 & 9 \\
\hline Arcaico o Formativo? & 1 & 0 & 1 \\
\hline Transición Arcaico-Formativo & 1 & 1 & 2 \\
\hline Formativo & 19 & 20 & 39 \\
\hline Medio & 1 & 5 & 6 \\
\hline Intermedio Tardío & 26 & 15 & 41 \\
\hline Tardío & 1 & 0 & 1 \\
\hline Histórico & 18 & 7 & 25 \\
\hline Total & 76 & 48 & $124 / 46.96 \%$ \\
\hline Prehispánico Indeterminado & 52 & 2 & $54 / 20.45 \%$ \\
\hline Arcaico y Formativo & 5 & 0 & 5 \\
\hline Arcaico a Medio & 0 & 1 & 1 \\
\hline Arcaico a Intermedio Tardío & 1 & 4 & 5 \\
\hline Arcaico a Histórico & 1 & 0 & 1 \\
\hline Formativo y Medio & 0 & 2 & 2 \\
\hline Formativo a Intermedio Tardío & 7 & 15 & 22 \\
\hline Formativo a Tardío & 0 & 1 & 1 \\
\hline Formativo a Histórico & 4 & 5 & 9 \\
\hline Medio e Intermedio Tardío & 3 & 12 & 15 \\
\hline Medio a Histórico & 1 & 5 & 6 \\
\hline Intermedio Tardío y Tardío & 1 & 4 & 5 \\
\hline Intermedio Tardío a Histórico & 9 & 5 & 14 \\
\hline Total & 32 & 54 & $86 / 32.57 \%$ \\
\hline TOTAL & 160 & 104 & $264 / 100.00 \%$ \\
\hline
\end{tabular}

Cuadro 1. Componentes de los sitios registrados. 
Composición. La gran mayoría de los sitios resultó ser unicomponente (46.96\%), y un $32.57 \%$ bi o multicomponente, en tanto un $20.45 \%$ aunque prehispánico, careció de indicadores cronológicosculturales (Cuadro 1).

En cuanto a los sitios monocomponentes, existen 39 sitios formativos, 19 en las quebradas (18 en la cuenca del Vilama y uno en Pelun), y 20 en los oasis (dos en Larache, dos en Sequitor, dos en Solor, uno en Coyo, cuatro en Cucuter, uno en Poconche, seis en Beter y dos en Tulor); una estructura en el Vilama puede corresponder al Arcaico o al Formativo, en tanto de la transición entre estos períodos hay dos sitios, una cantera-taller en Vilama y un asentamiento disperso en Poconche.

Entre los sitios bicomponentes y multicomponentes se encuentran cinco sitios en Vilama que se ocupan desde al Arcaico al Formativo; un sitio en Poconche que se ocupa desde el Arcaico al Período Medio; cinco sitios con ocupaciones que van desde el Arcaico al Intermedio Tardío, uno en el Vilama y cuatro en los oasis (dos sitios en Beter, uno es Tchaputchayna con cementerio, y dos en Poconche); y uno, sólo Calar en Vilama que tiene una secuencia completa desde el Arcaico al Histórico.

Por otra parte, entre los que inician sus ocupaciones durante el Formativo, hay dos en Cucuter que lo hacen hasta el Período Medio; hasta el Intermedio Tardío hay un total de 22, 15 en los oasis y siete en el Vilama, cuatro en Poconche, ocho en Beter y uno en Cucuter; y hasta el Histórico sólo uno en Beter.

Considerando el acotado espacio prospectado, resulta interesante que gran parte de las ocupaciones sean de carácter monocomponente, y un porcentaje menor presente reocupaciones. También es sugerente que la mayor cantidad de sitios monocomponentes sean aquellos asignables al Formativo (en el Vilama y en los oasis), al Intermedio Tardío (en el Vilama y en el oasis), y al Histórico (en los oasis), señalando en los tres casos un cambio en las concepciones sobre el manejo del espacio y los recursos.

Categorías y emplazamiento. Ahora, respecto de las categorías de sitios registrados en la cuenca del Vilama y en los oasis bajos, estas suman 19, siendo los más numerosos los asentamientos $(60.15 \%)$, y entre estos los Asentamientos Discretos No Estructurados (21.48\%), los Asentamientos Discretos Estructurados (11.48\%) y las Estancias (8.88\%), luego siguen el resto con porcentajes bajo el 7\%; la categoría Estructura también cuenta con una buena representación $(16.66 \%)$ pero, lamentablemente, la mayoría carece de indicadores cronológicos culturales. Bajo el $4 \%$ se encuentra el resto de las categorías de sitios (Cuadro 2).

La mayoría de los sitios se encuentra en la cuenca del Vilama $(61.48 \%$ ) y el restante $38.51 \%$, en los oasis. Como es obvio, por el tipo de materiales disponibles para construir, la mayoría de los asentamientos estructurados (27.01\%) se ubicó en la cuenca del Vilama, en cambio los no estructurados se emplazaron en los oasis (28.88\%), siendo equilibrada la cantidad de sitios habitacionales en ambas zonas. Por otra parte, debido al tipo de paisaje, hay sitios exclusivos de la quebrada de Vilama (estancias, estructuras, paraderos ocasionales, abrigos bajo roca, marcas, apachetas, mochaderos, arte rupestre, vías de circulación) y de los oasis (asentamientos no estructurados, fundiciones).

En cuanto a los sitios habitacionales, todos los Asentamientos Complejos Estructurados (5.92\%), salvo uno en Poconche, corresponden al Formativo. Doce de ellos se emplazan en el Vilama, en cuyo caso se estructuran con muros de piedra (uno de ellos, Calar, con cementerio incluido), y cuatro en los oasis (dos en Poconche y dos en Tulor), donde lo hacen con muros de adobe o quizás quincha; los Asentamientos Discretos Estructurados (11.48\%) se emplazan al igual que los anteriores principalmente en el Vilama, y solo cinco en los oasis (dos en Poconche, uno en Tulor, uno en Coyo y uno en Beter) y corresponden a varios períodos; de los Asentamientos Dispersos Estructurados (4.07\%), todos se emplazan en el Vilama siendo asignables a varios períodos; los Asentamientos Discretos No Estructurados $(21.48 \%)$ se encuentran sin excepción en los oasis (16 en Cucuter, 18 en Poconche y 24 en Beter) y corresponden a todos los períodos; los Asentamientos Dispersos No Estructurados se emplazan en su totalidad (7.40\%) en los oasis (cinco en Cucuter, seis en Poconche, cinco en Beter, uno en Tulor, uno en Sequitor y uno en Yaye) y son asignables a varios períodos. Tres de 


\begin{tabular}{|lrrrrrr|r|}
\hline Categorias de Sitios & \multicolumn{2}{c}{ Vilama } & \multicolumn{2}{c}{ Oasis } & \multicolumn{2}{c}{ Total } \\
\hline Asentamiento Complejo Estructurado & 12 & $4.44 \%$ & 4 & $1.48 \%$ & 16 & $5.92 \%$ \\
Asentamiento Discreto Estructurado & 26 & $9.62 \%$ & 5 & $1.85 \%$ & 31 & $11.48 \%$ \\
Asentamiento Disperso Estructurado & 11 & $4.07 \%$ & 0 & & 11 & $4.07 \%$ \\
Estancia & 24 & $8.88 \%$ & 0 & & 24 & $8.88 \%$ \\
Asentamiento Discreto No Estructurado & 0 & & 58 & $21.48 \%$ & 58 & $21.48 \%$ \\
Asentamiento Disperso No Estructurado & 0 & & 20 & $7.40 \%$ & 20 & $7.40 \%$ \\
Taller (o Cantera-taller) & 17 & $6.29 \%$ & 1 & $0.37 \%$ & 18 & $6.66 \%$ \\
Estructura/s & 45 & $16.66 \%$ & 0 & & 45 & $16.66 \%$ \\
Paradero ocasional & 9 & $3.33 \%$ & 0 & & 9 & $3.33 \%$ \\
Fundición & 0 & & 7 & $2.59 \%$ & 7 & $2.59 \%$ \\
Abrigo bajo roca & 5 & $1.85 \%$ & 0 & & 5 & $1.85 \%$ \\
Marca & 5 & $1.85 \%$ & 0 & & 5 & $1.85 \%$ \\
Apacheta & 1 & $0.37 \%$ & 0 & & 1 & $0.37 \%$ \\
Huaqui & 0 & & 1 & $0.37 \%$ & 1 & $0.37 \%$ \\
Mochadero & 3 & $1.11 \%$ & 0 & \multirow{2}{*}{$2.96 \%$} & 3 & $1.11 \%$ \\
Cementerio & 1 & $0.37 \%$ & 8 & & $3.33 \%$ \\
Arte rupestre & 5 & $1.85 \%$ & 0 & & 5 & $1.85 \%$ \\
Vía de circulación & 1 & $0.37 \%$ & 0 & & 1 & $0.37 \%$ \\
Registro aislado & 1 & $0.37 \%$ & 0 & & 1 & $0.37 \%$ \\
\hline Total & $\mathbf{1 6 6}$ & $\mathbf{6 1 . 4 8 \%}$ & $\mathbf{1 0 4}$ & $\mathbf{3 8 . 5 1 \%}$ & $\mathbf{2 7 0}$ & $\mathbf{1 0 0 . 0 0 \%}$ \\
\hline
\end{tabular}

Cuadro 2. Categorías de sitios registrados en la cuenca del Vilama y en los oasis bajos. ${ }^{7}$

ellos, tienen además cementerio atribuible al Formativo (Poconche, Tchaputchayna y Sequitor Alambrado Oriental), y dos de ellos, fundición, probablemente del Intermedio Tardío. Además, se registraron 24 estancias $(8.88 \%)$ en el Vilama con componentes intermedios tardíos o etnográficos.

Se contabilizaron 18 (6.66\%) talleres o canterastalleres -dos con estructuras- la mayoría en el Vilama, habiendo solo uno en Poconche, y casi todos de data indeterminada.

En el Vilama se registraron 45 estructuras $(16.66 \%)$-dos de ellas en canteras-taller- de una variedad de períodos y también bastantes de data indeterminada; nueve paraderos ocasionales, seis de data indeterminada y tres con evidencias del Intermedio Tardío, algunas asociadas a la huella caravanera que entra a San Pedro; cinco marcas, dos del Intermedio Tardío y tres de data prehispánica indeterminada; y cinco abrigos bajo roca de diferentes períodos. En los oasis, hubo siete fundiciones en Beter, del Período Medio y/o

7 El número de categorías es mayor al total de sitios mostrado en el Cuadro 1, pues algunos incluyen dos categorías: p.e., cantera-taller y estructuras, asentamiento y cementerio, o asentamiento y fundición. del Intermedio Tardío, dos de ellas en asentamientos. Tres presentan evidencias del Formativo.

Entre los sitios ceremoniales se cuentan: una apacheta en la huella Vilama-Guatin correspondiente al Intermedio Tardío; un "huaqui" histórico en Beter, probablemente vinculado al "Pueblo de Indios" o Beter-1; tres mochaderos en el Vilama, cuando cambia el paisaje entrando a los oasis de San Pedro. Tres corresponden al Intermedio Tardío y uno tiene evidencias formativas e históricas. Nueve cementerios, siete en los oasis (Larache, Larache Acequia, Sequitor Alambrado Acequia, Solor-3 [Piso Inferior] y Solor-6 [Piso Inferior] y Poconche), tres integrados en asentamientos dispersos no estructurados (Poconche, Tchaputchayna y Sequitor Alambrado Oriental) y uno en un asentamiento estructurado en Vilama (Calar).

Además, se registraron cinco sitios con arte rupestre en Vilama, tres asignables al Formativo, uno Histórico y uno de cronología indeterminada, un camino atribuible al Inca que cruza el Vilama hacia Chaxas, y un registro aislado histórico en Cucuter.

Secuencia. Ahora, considerando para cada período el total de ocupaciones tanto de los sitios 


\begin{tabular}{|lrrrrrr|}
\hline Período & \multicolumn{2}{c}{ Vilama } & \multicolumn{2}{c}{ Oasis } & \multicolumn{2}{c|}{ Total } \\
\hline Arcaico & 15 & $3.85 \%$ & 5 & $1.28 \%$ & 20 & $5.14 \%$ \\
Transición Arcaico-Formativo & 4 & $1.02 \%$ & 1 & $0.25 \%$ & 5 & $1.28 \%$ \\
Formativo & 39 & $10.02 \%$ & 46 & $11.82 \%$ & 85 & $21.85 \%$ \\
Medio & 7 & $1.79 \%$ & 43 & $11.05 \%$ & 50 & $12.85 \%$ \\
Intermedio Tardío & 49 & $12.59 \%$ & 60 & $15.42 \%$ & 109 & $28.02 \%$ \\
Tardío & 3 & $0.77 \%$ & 9 & $2.31 \%$ & 12 & $3.08 \%$ \\
Histórico & 21 & $5.39 \%$ & 33 & $8.48 \%$ & 54 & $13.88 \%$ \\
Prehispánico Indeterminado & 52 & $13.36 \%$ & 2 & $0.51 \%$ & 54 & $13.88 \%$ \\
\hline Total & $\mathbf{1 9 0}$ & $\mathbf{4 8 . 8 4 \%}$ & $\mathbf{1 9 9}$ & $\mathbf{5 1 . 1 5 \%}$ & $\mathbf{3 8 9}$ & $\mathbf{1 0 0 . 0 0 \%}$ \\
\hline
\end{tabular}

Cuadro 3. Cantidad y porcentaje de ocupaciones por período en la cuenca del Vilama y en los oasis bajos.

monocomponentes como multicomponentes (Cuadro 1), el Cuadro 3 indica que las más numerosas son aquellas formativas $(21.85 \%)$ e intermedias tardías $(28.02 \%)$, seguidas por las históricas (13.88\%), del Período Medio (12.85\%), arcaicas (5.14\%) y, por último, las de la transición Arcaico-Formativo (1.28\%). Por su parte, la ocupación del Vilama presenta pulsaciones entre cada período, siendo alta en el Formativo, bajando en el Medio, subiendo en el Intermedio Tardío, bajando en el Tardío y volviendo a subir en el Histórico. En contraste, la ocupación de los oasis mantiene un porcentaje alto relativamente parejo desde el Formativo al Intermedio Tardío, bajando en el Tardío y volviendo a subir en el Histórico. Sin embargo, hay que considerar que aquellas del Medio en adelante pueden subir su representación al considerar los oasis centrales y altos de San Pedro de Atacama (ver Llagostera y Costa 1999).

La transición Arcaico-Formativo está representada por cinco ocupaciones (1.28\%), cuatro en el Vilama $(80 \%)$ y una en Poconche (20\%). En el Vilama hay un Asentamiento Complejo Estructurado que continúa en uso durante el Formativo Temprano, dos canteras-taller, una de las cuales se viene usando desde el Arcaico, y una estructura (Cuadro 4). Un
Asentamiento Disperso No Estructurado se emplaza en Poconche, cerca de los sitios formativos que veremos más adelante.

Para el Formativo en general, el Cuadro 3 muestra un alto porcentaje de ocupaciones $(21.85 \%)$, las cuales presentan una leve mayor representación en los oasis $(56.66 \%)$ que en el Vilama (43.33\%), donde continúan siendo ocupados los mismos espacios del Arcaico. Por su parte, los oasis bajos exhiben un aumento significativo de ocupaciones en momentos más tempranos observándose en general, una evidente mayor variabilidad de categorías, como más tipos de asentamientos, abrigos bajo roca, arte rupestre, fundiciones, cementerios y mochadero.

La mayor cantidad de sitios la constituyen los asentamientos $(74.44 \%)$, presentes en ambas zonas, aunque la mayoría se emplaza en los oasis (44.44\%), donde aquellos estructurados lo estarían en materiales perecederos. La mayoría de los cementerios está en los oasis (8.88\%), siendo algunos integrados en sectores de asentamientos (Poconche, Tchaputchayna, Sequitor Alambrado Oriental), al igual que el único sitio de este tipo registrado en el Vilama (Calar).

\begin{tabular}{|c|c|c|c|c|c|c|}
\hline \multirow{2}{*}{$\begin{array}{l}\text { Categoría de sitios } \\
\text { Asentamiento Complejo Estructurado }\end{array}$} & \multicolumn{2}{|c|}{ Vilama } & \multicolumn{2}{|c|}{ Oasis } & \multicolumn{2}{|c|}{ Total } \\
\hline & 1 & $20 \%$ & 0 & & 1 & $20 \%$ \\
\hline Asentamiento Disperso No Estructurado & 0 & & 1 & $20 \%$ & 1 & $20 \%$ \\
\hline Cantera-taller & 2 & $40 \%$ & 0 & & 2 & $40 \%$ \\
\hline Estructura & 1 & $20 \%$ & 0 & & 1 & $20 \%$ \\
\hline Total & 4 & $80 \%$ & 1 & $20 \%$ & 5 & $100 \%$ \\
\hline
\end{tabular}

Cuadro 4. Categorías de sitios durante la transición Arcaico-Formativo. 
En efecto, sorprende la cantidad de sitios residenciales registrados para este período (Cuadro 5). Las categorías de asentamientos estructurados, por sus características, se sitúan mayormente en el Vilama (24.44\%). Algunos de ellos se emplazan sobre ocupaciones arcaicas; sin embargo, también encontramos edificaciones de adobe en el oasis y arquitectura perecedera (4.44\%). Por otra parte, las categorías de asentamientos no estructurados se emplazan únicamente en los oasis $(40 \%)$, estando dos de ellos sobre ocupaciones arcaicas. El caso de las estancias es distinto, pues las construcciones del Intermedio Tardío se encuentran en lugares que presentan ocupaciones formativas tempranas que no nos fue posible caracterizar.

Finalmente, hay categorías de sitios poco representadas (bajo 5.55\%) emplazadas exclusivamente en el Vilama (una cantera-taller, un alero bajo roca, un mochadero, cinco estructuras y tres sitios de arte rupestre), así como tres fundiciones presentes exclusivamente en los oasis.

Al respecto, Llagostera y Costa (1999) señalan que los distintos patrones de asentamiento existentes a partir de los inicios de la era en los oasis, estuvieron relacionados con el manejo del agua y con la disponibilidad de espacios coloni- zables. Dada la generalidad de los indicadores mencionados por estos autores que no permite segmentar en fases al Formativo, consideraremos en este amplio lapso todos los sitios registrados por ellos dentro del Período Temprano. Señalan que el asentamiento humano en los oasis aparece muy relacionado con el ingreso del maíz, emplazándose los sitios al pie de puna, cerca de la desembocadura de ríos, en el borde suroeste de los oasis de San Pedro, específicamente en Tulor. Tal situación sin duda contrasta con nuestros resultados mostrados en la Figura 1, en la cual resulta elocuente la cantidad de asentamientos del período registrados en ambos sectores, ampliándose aquellos de la quebrada, y también en los oasis, donde no están sólo en Tulor, sino además en Cucuter, Poconche y Beter. Nuestro registro indica que el asentamiento precede al ingreso del maíz, relacionándose más bien con prácticas de recolección que deben haber sido importantes para observar en los meses de verano -en los cuales se realiza la recolección de chañar y de algarrobo- las condiciones apropiadas para las primeras prácticas hortícolas, como, por ejemplo, crecida de caudal y eliminación de sales del suelo, cubierta vegetal adecuada para prevenir heladas en los primeros meses y aumento de temperatura, entre otros.

\begin{tabular}{|lrrrrrr|}
\hline Categoría de sitios & \multicolumn{2}{c}{ Vilama } & \multicolumn{2}{c}{ Oasis } & \multicolumn{2}{c|}{ Total } \\
\hline Asentamiento Complejo Estructurado & 12 & $13.33 \%$ & 3 & $3.33 \%$ & 15 & $16.66 \%$ \\
Asentamiento Discreto Estructurado & 10 & $11.11 \%$ & 1 & $1.11 \%$ & 11 & $12.22 \%$ \\
Asentamiento Disperso Estructurado & 3 & $3.33 \%$ & 0 & & 3 & $3.33 \%$ \\
Asentamiento Discreto No Estructurado & 0 & & 25 & $27.77 \%$ & 25 & $27.77 \%$ \\
Asentamiento Disperso No Estructurado & 0 & & 11 & $12.22 \%$ & 11 & $12.22 \%$ \\
Estancia & 2 & $2.22 \%$ & 0 & & 2 & $2.22 \%$ \\
Cantera-taller & 1 & $1.11 \%$ & 0 & & 1 & $1.11 \%$ \\
Estructura & 5 & $5.55 \%$ & 0 & & 5 & $5.55 \%$ \\
Fundición & 0 & & 3 & $3.33 \%$ & 3 & $3.33 \%$ \\
Abrigo bajo roca & 1 & $1.11 \%$ & 0 & & 1 & $1.11 \%$ \\
Mochadero & 1 & $1.11 \%$ & 0 & & 1 & $1.11 \%$ \\
Cementerio & 1 & $1.11 \%$ & 8 & $8.88 \%$ & 9 & $10 \%$ \\
Arte rupestre & 3 & $3.33 \%$ & 0 & & 3 & $3.33 \%$ \\
\hline Total & $\mathbf{3 9}$ & $\mathbf{4 3 . 3 3 \%}$ & $\mathbf{5 1}$ & $\mathbf{5 6 . 6 6 \%}$ & $\mathbf{9 0}$ & $\mathbf{1 0 0 . 0 0 \%}$ \\
\hline
\end{tabular}

Cuadro 5. Categorías de sitios durante el Formativo. ${ }^{8}$

8 La cantidad de sitios mostrada en este cuadro es menor al total de ocupaciones presentada en el Cuadro 6, pues aquí se consideró el Formativo en su conjunto, sin segmentar las ocupaciones ocurridas en distintos momentos en un mismo sitio. 
APROXIMACION AL ASENTAMIENTO HUMANO TEMPRANO...

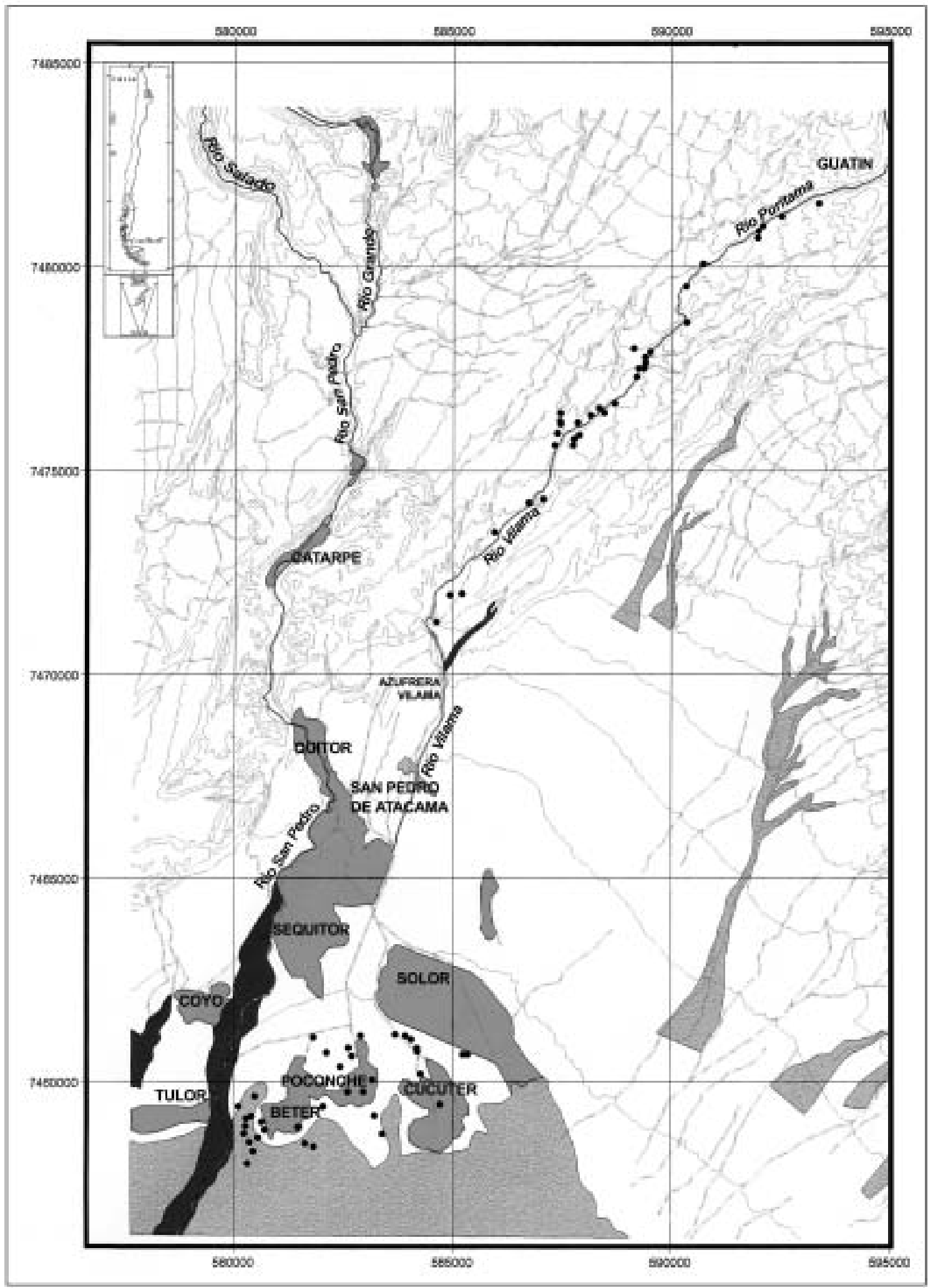

Figura 1. Mapa que muestra las ocupaciones del Período Formativo registradas en la quebrada del Vilama y los oasis de San Pedro de Atacama. 


\begin{tabular}{|lrrrrrr|}
\hline \multirow{2}{*}{ Período } & \multicolumn{2}{c}{ Vilama } & \multicolumn{2}{c|}{ Oasis } & \multicolumn{2}{c|}{ Total } \\
\hline Formativo Temprano & 29 & $24.78 \%$ & 26 & $22.22 \%$ & 55 & $47 \%$ \\
Formativo Medio & 5 & $4.27 \%$ & 9 & $7.69 \%$ & 14 & $11.96 \%$ \\
Formativo Tardío & 12 & $10.25 \%$ & 36 & $30.76 \%$ & 48 & $41.02 \%$ \\
\hline Total & $\mathbf{4 6}$ & $\mathbf{3 9 . 3 1 \%}$ & $\mathbf{7 1}$ & $\mathbf{6 0 . 6 8 \%}$ & $\mathbf{1 1 7}$ & $\mathbf{1 0 0 . 0 0 \%}$ \\
\hline
\end{tabular}

Cuadro 6. Distribución de las ocupaciones durante el Período Formativo.

También se observó que el período cuenta con una mayoría de ocupaciones monocomponentes tanto en el Vilama como en los oasis, lo que junto a una mayor diversidad de sitios, por una parte, muestra un cambio en el modo de vida, en las concepciones sobre el manejo del territorio y sus recursos, y por otra, indica la articulación complementaria de ambas zonas, la que debió ir cambiando desde el momento temprano del período al tardío del mismo. El Cuadro 6 es claro en este sentido: durante el Formativo Temprano la quebrada de Vilama está un poco más representada que en los oasis; durante el Formativo Medio la proporción llega a ser levemente favorable a los oasis; para finalmente en el Formativo Tardío exhibir una clara desproporción entre ambas zonas, siendo ampliamente ocupados los oasis en desmedro de la quebrada

\section{Formativo Temprano (1300-350 DC)}

Durante el Formativo Temprano se detectaron 55 ocupaciones correspondientes al $47 \%$ del total (Cuadro 7). De éstas, el 52.72\% se emplazó en el Vilama, y el $47.27 \%$ en los oasis de Beter $(n=9)$, Cucuter $(n=6)$, Poconche $(n=6)$, Tulor $(n=2)$, Coyo, Solor y Yaye (una en cada uno). El 78.18\% se inaugura en este período, en tanto el $21.81 \%$ sigue utilizando los sitios del Arcaico.

Considerando las propuestas previas (Núñez 1995; Llagostera y Costa 1999), sorprendentemente, los asentamientos están mayormente representados en los oasis bajos $(45.45 \%)$ que en la quebrada (40\%), siendo en esta última donde se encuentra la mayor diversidad de categorías de sitios.

La mayoría de los Asentamientos Complejos Estructurados están en la quebrada de Vilama (20\%), uno de los cuales tiene integrado un cementerio (Calar) que, por sus contextos, es asignable al Formativo Tardío, en tanto un 5.45\% lo hace en Poconche y en Tulor. Lo mismo sucede con los Asentamientos Discretos Estructurados con un $14.54 \%$ en la quebrada y un $1.81 \%$ en Coyo. Todos los Asentamientos Dispersos Estructurados $(5.45 \%)$ se emplazan en el Vilama, siendo inicialmente construidos en el Arcaico. Por el contrario, todos los asentamientos no estructurados se emplazan en los oasis, ya sean los Discretos No Estructurados $(23.63 \%)$ o los Dispersos No Estructurados (14.54\%). Uno de ellos, Poconche ${ }^{9}$, integra a un cementerio asignable a este momento. Además, hay dos estancias construidas sobre ocupaciones formativas tempranas que fue imposible caracterizar.

Por su parte, la quebrada presenta una mayor diversidad de categorías de sitios como tres estructuras, una extensa cantera-taller (Loma Negra) y un sitio con arte rupestre, lo que a partir del registro Arcaico señala un conocimiento de ese ámbito, anterior al de los oasis. Por otro lado, en ellos, hay un cementerio en Solor-6 que, debido a su mala conservación y a la disminuida calidad de los datos, no permite asignarlo en forma fehaciente a este momento temprano.

En la quebrada, los asentamientos tienden a agruparse en el segmento Ghatchi-Calar sobre mesetas interfluviales de pendiente suave y con un buen dominio visual del entorno, correspondientes a las primeras terrazas del río cuyo lecho en estos sectores se abre dando lugar a espacios aptos para el mantenimiento de camélidos, y a vegas y/o vertientes. Las quebradas que delimitan los asentamientos empiezan a marcarse con arte rupestre, el que además se emplaza cerca de vertientes (02-Vi-83) (Figura 2 y Tabla 1 al final).

9 De este sitio fechamos cerámica del tipo Los Morros en 870 AC [UCTL 1611], 845 AC [UCTL 1612] y 360 AC [UCTL 1610]). 
APROXIMACION AL ASENTAMIENTO HUMANO TEMPRANO...

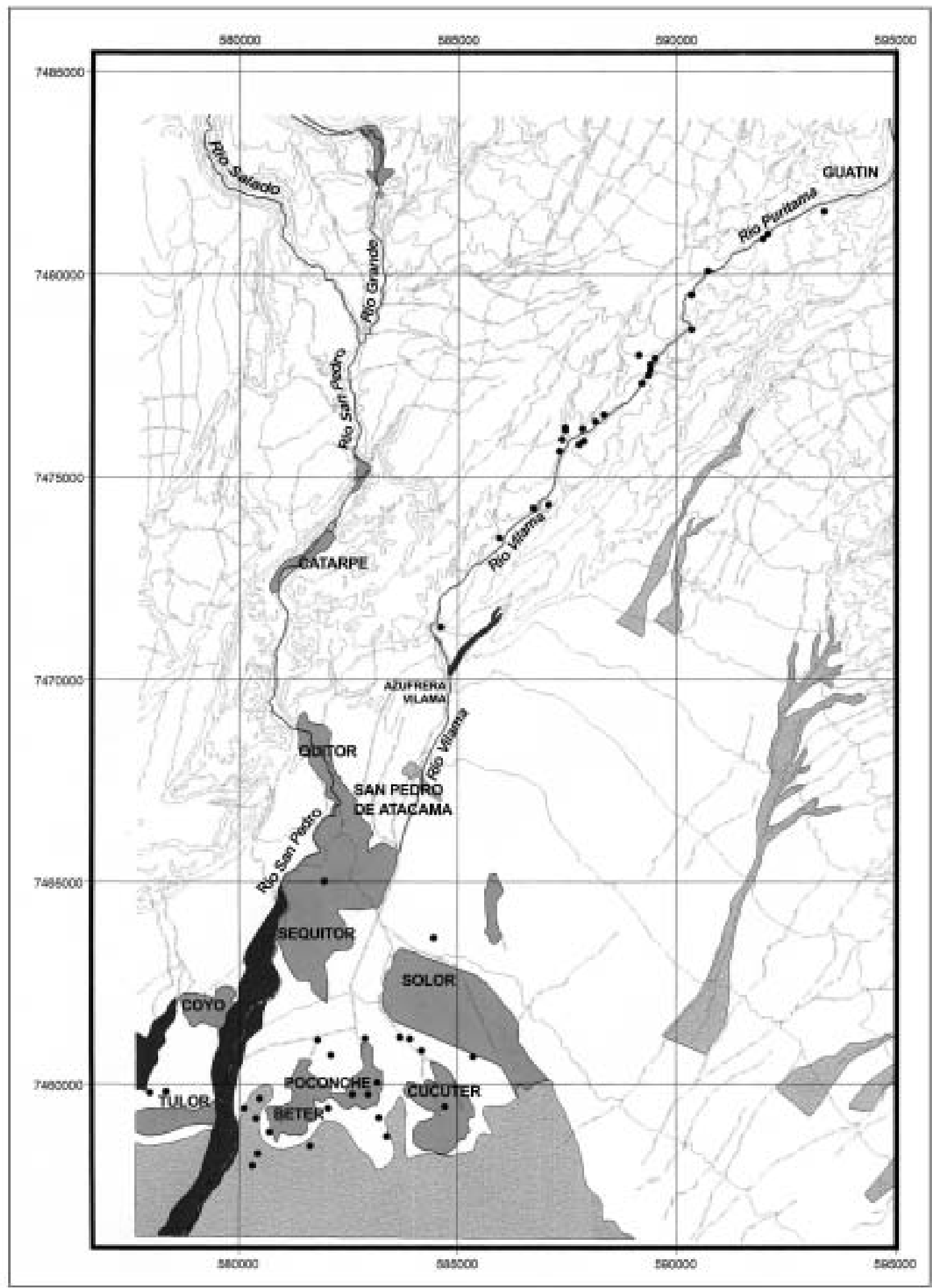

Figura 2. Ocupaciones correspondientes al Formativo Temprano. 


\begin{tabular}{|c|c|c|c|c|c|c|}
\hline \multirow{2}{*}{$\begin{array}{l}\text { Categoría de sitios } \\
\text { Asentamiento Complejo Estructurado }\end{array}$} & \multicolumn{2}{|c|}{ Vilama } & \multicolumn{2}{|c|}{ Oasis } & \multicolumn{2}{|c|}{ Total } \\
\hline & 11 & $20 \%$ & 3 & $5.45 \%$ & 14 & $25.45 \%$ \\
\hline Asentamiento Discreto Estructurado & 8 & $14.54 \%$ & 1 & $1.81 \%$ & 9 & $16.36 \%$ \\
\hline Asentamiento Disperso Estructurado & 3 & $5.45 \%$ & 0 & & 3 & $5.45 \%$ \\
\hline Asentamiento Discreto No Estructurado & 0 & & 13 & $23.63 \%$ & 13 & $23.63 \%$ \\
\hline Asentamiento Disperso No Estructurado & 0 & & 8 & $14.54 \%$ & 8 & $14.54 \%$ \\
\hline Estancia & 2 & $3.63 \%$ & 0 & & 2 & $3.63 \%$ \\
\hline Cantera-taller & 1 & $1.81 \%$ & 0 & & 1 & $1.81 \%$ \\
\hline Estructura & 3 & $5.45 \%$ & 0 & & 3 & $5.45 \%$ \\
\hline Cementerio & 0 & & 1 & $1.81 \%$ & 1 & $1.81 \%$ \\
\hline Arte rupestre & 1 & $1.81 \%$ & 0 & & 1 & $1.81 \%$ \\
\hline Total & 29 & $52.72 \%$ & 26 & $47.27 \%$ & 55 & $100.00 \%$ \\
\hline
\end{tabular}

Cuadro 7. Categorías de sitios durante el Formativo Temprano.

El emplazamiento de Ghatchi-2 es muy sugerente, pues se encuentra en la meseta, inmediatamente bajo la Loma Negra, es decir, adyacente al lugar de aprovisionamiento de basalto, y conectado con otros asentamientos contemporáneos situados en cotas más altas, como Pelun.

Por otra parte, en los oasis, los asentamientos constituyen prácticamente la única categoría de sitios, y se emplazan casi exclusivamente en Cucuter, Poconche, Beter, y en menor proporción en Tulor. La ausencia de piedras hasta hoy determina la construcción en barro y quincha, encontrándonos con evidencias de este sistema constructivo en algunos sitios, aunque resta comprobar su asociación temprana. Por otra parte, la construcción en adobe puede desmoronarse y fundirse con la lluvia observándose posteriormente montículos de barro. Tulor y parte de Coyo tuvieron mejor suerte puesto que los muros de barro pudieron conservarse debido a que las dunas los cubrieron. La ubicación de todos estos sitios sugiere el aprovechamiento de los desaguies de los ríos, principalmente del San Pedro para el desarrollo de actividades hortícolas, en coincidencia con la recolección estacional de los frutos de chañares y algarrobos. Esto es particularmente visible en la mayor ocupación de Beter más que Cucuter y Poconche. Los dos últimos pueden haber constituido una etapa experimental respecto a los cultivos debido a que se encuentran próximos a los desagües del salino Vilama, en contraposición al San Pedro. Por último, la existencia del primer cementerio de los oasis en Poconche con cuerpos recostados en cuclillas y cerámica LMS, señala una diferencia con la quebrada, al seleccionar un lugar en el asen- tamiento donde depositar a los muertos, dotando a los oasis de una significación particular.

\section{Formativo Medio (350 AC-100 DC)}

Durante el Formativo Medio se detectaron 14 ocupaciones correspondientes al $11.96 \%$ del total de sitios registrados (Cuadro 6). Este bajo porcentaje se debe, probablemente, a que los indicadores de este momento están contenidos en parte en el anterior, y en parte en el siguiente, de manera que no resulta fácil distinguirlo en superficie en ausencia de asociaciones contextuales más claras.

El Cuadro 8 indica que sólo el $35.71 \%$ se emplazó en el Vilama, y el $64.28 \%$ en los oasis de Beter $(n=3)$, Tulor (2), Poconche, Sequitor y Yaye (uno en cada uno). Los asentamientos están mayormente representados en los oasis bajos (50\%) que en la quebrada (28.57\%), donde se siguen utilizando los sitios del segmento Ghatchi-Calar y la cantera-taller de Loma Negra.

La mayoría de los Asentamientos Complejos Estructurados se emplazan en el Vilama (28.57\%), uno de los cuales tiene integrado un cementerio (Calar) que ha sido asignado al Formativo Tardío. La única fecha de $140 \pm 70 \mathrm{AC}$ de este asentamiento (Orellana 1988-89; Llagostera 1988), lo sitúa en esta fase. Por otra parte, en los oasis ya están en pleno uso los sitios Tulor-1 y Tulor-4 junto a sitios no estructurados emplazados en Beter $(n=3)$, Poconche $(\mathrm{n}=1)$ y Yaye $(\mathrm{n}=1)$. En este ámbito, ahora surgen dos nuevos cementerios: Larache Acequia y Sequitor Alambrado Acequia, el pri- 


\begin{tabular}{|llrrrrr|}
\hline Categoría de sitios & \multicolumn{2}{c}{ Vilama } & \multicolumn{2}{c}{ Oasis } & \multicolumn{2}{c|}{ Total } \\
\hline Asentamiento Complejo Estructurado & 4 & $28.57 \%$ & 2 & $14.28 \%$ & 6 & $42.85 \%$ \\
Asentamiento Discreto No Estructurado & 0 & & 1 & $7.14 \%$ & 1 & $7.14 \%$ \\
Asentamiento Disperso No Estructurado & 0 & & 4 & $28.57 \%$ & 4 & $28.57 \%$ \\
Cantera-taller & 1 & $7.14 \%$ & 0 & & 1 & $7.14 \%$ \\
Cementerio & 0 & & 2 & $14.28 \%$ & 2 & $14.28 \%$ \\
\hline Total & $\mathbf{5}$ & $\mathbf{3 5 . 7 1 \%}$ & $\mathbf{9}$ & $\mathbf{6 4 . 2 8 \%}$ & $\mathbf{1 4}$ & $\mathbf{1 0 0 . 0 0 \%}$ \\
\hline
\end{tabular}

Cuadro 8. Categorías de sitios durante el Formativo Medio.

mero de los cuales tiene contextos destacables (Le Paige 1964). La distribución de los sitios indica que en los oasis se empieza a extender la ocupación en sus sectores centrales, como Yaye y Larache (Figura 3).

La contemporaneidad entre los asentamientos de Tulor-1 y Tulor-4 en los oasis, y Calar en la quebrada, plantea para estos momentos la existencia de prácticas económicas complementarias de recolección y agricultura de campos inundados hacia los oasis bajos, junto a estrategias de pastoreo hacia el sector de Calar-Ghatchi, delimitando hasta aquí el manejo del territorio propiamente san pedrino.

\section{Formativo Tardío (100-500 DC)}

Durante el Formativo Tardío se detectaron 48 ocupaciones correspondientes al $41.02 \%$ del total del período (Cuadro 6). De éstas, como lo muestra el Cuadro 9, el 25\% se emplazó en la quebrada de Vilama y el $75 \%$ en los oasis, habiendo 17 en Beter, siete en Cucuter, cinco en Poconche, dos en Solor, y una en Tulor, Coyo, Larache y Sequitor. Además, es sugerente que un tercio de las ocupaciones se inaugure en este período principalmente en los oasis $(27.08 \%$ contra un $4.16 \%$ en Vilama), en tanto el $68.75 \%$ sigue utilizando los sitios con ocupaciones previas (Figura 4).

Los asentamientos están mayormente representados en los oasis bajos (85.41\%), pero es en la quebrada donde se encuentra la mayor diversidad de categorías de sitios. En fecto, se registraron siete Asentamientos Complejos Estructurados (seis en Vilama, uno de los cuales tiene integrado un cementerio [Calar] que por sus contextos puede ser asignado a este momento, aunque la posición de los difuntos muestra continuidad con aquellos del cementerio formativo temprano de Poconche, y uno en Tulor-1); tres Asentamientos Discretos Estructurados (dos en Vilama y uno en Coyo); exclusivamente en los oasis 19 Asentamientos Discretos No Estructurados (10 en Beter, seis en Cucuter y tres en Poconche) y 10 Asentamientos Dispersos No Estructurados (cinco en Beter, y en Poconche, Cucuter, Yaye, y Sequitor, uno en cada uno); por último hay en el Vilama una estancia construida sobre componentes formativos.

Se sigue utilizando la cantera-taller de Loma Negra; y surge un nuevo sitio con arte rupestre en los inicios de la quebrada del Loro, cerca de Ghatchi, y se continúa utilizando un panel que presentaba iconografía formativa temprana, al igual que una estructura.

Se crean dos cementerios en los oasis (Solor-3, piso inferior y Larache) y se sigue utilizando el de Solor-6. Además surge una fundición de cobre, y otras dos integradas en dos asentamientos de Beter también pueden asignarse a este momento.

Sin duda, la ocupación de los espacios quebradeños empieza a disminuir, especialmente los asentamientos, permaneciendo ocupados Pelun, Calar, Ghatchi-1B, dos más en el sector de Ghatchi y uno al norte de Loma Negra, en el sector de Incapite. En Calar es sugerente el enterramiento posterior de individuos, quizás señalando cuando la ocupación de este ámbito disminuye pero, al mismo tiempo, hay evidencias de prácticas agrícolas cercanas al lecho, cierta propiedad de los oasis sobre la quebrada media.

Esta situación difiere de aquella informada por Núñez y colaboradores (1999) para Puripica, donde las primeras ocupaciones formativas datan de 
CAROLINA AGÜERO P.

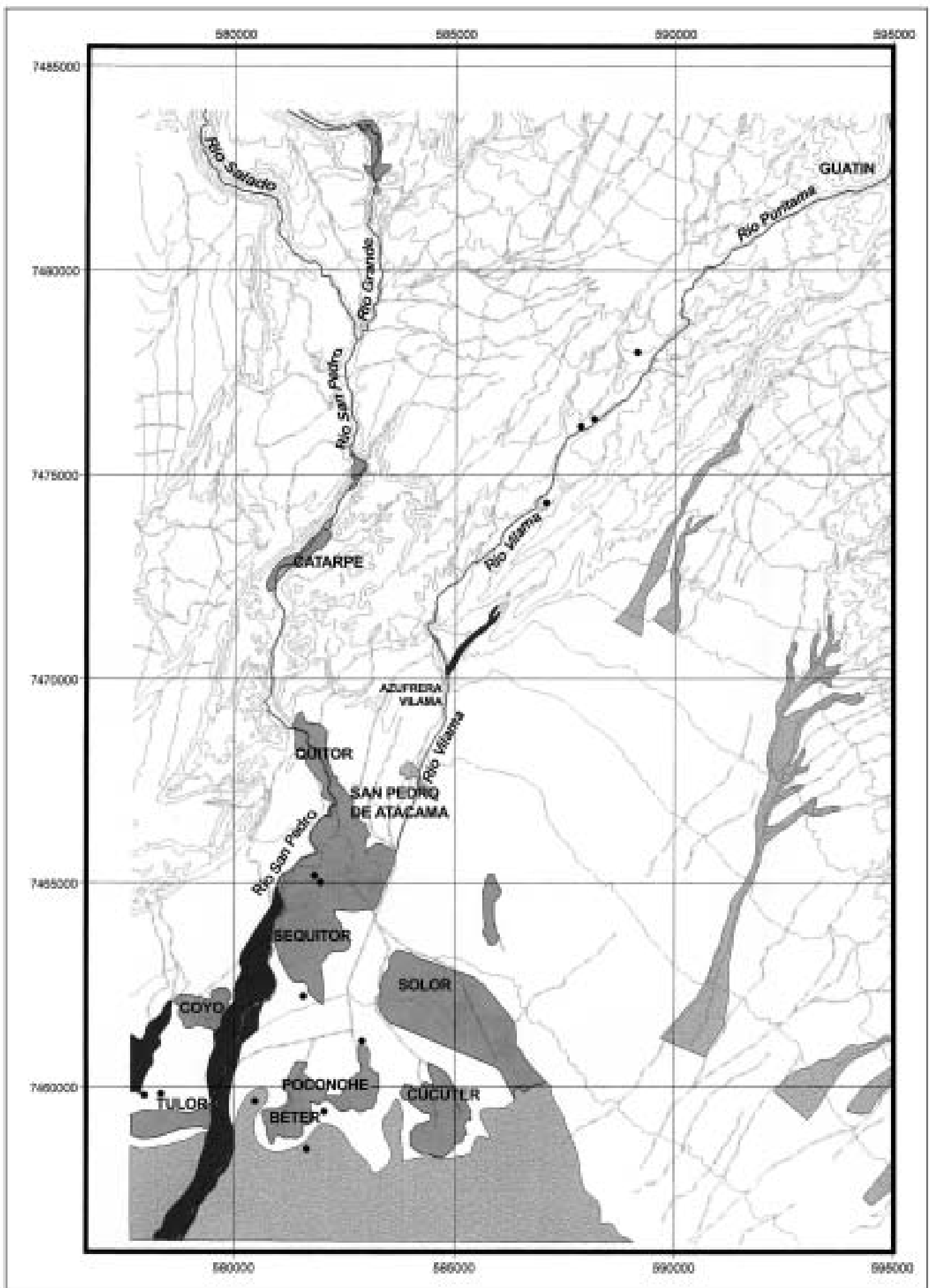

Figura 3. Ocupaciones correspondientes al Formativo Medio 
APROXIMACION AL ASENTAMIENTO HUMANO TEMPRANO...

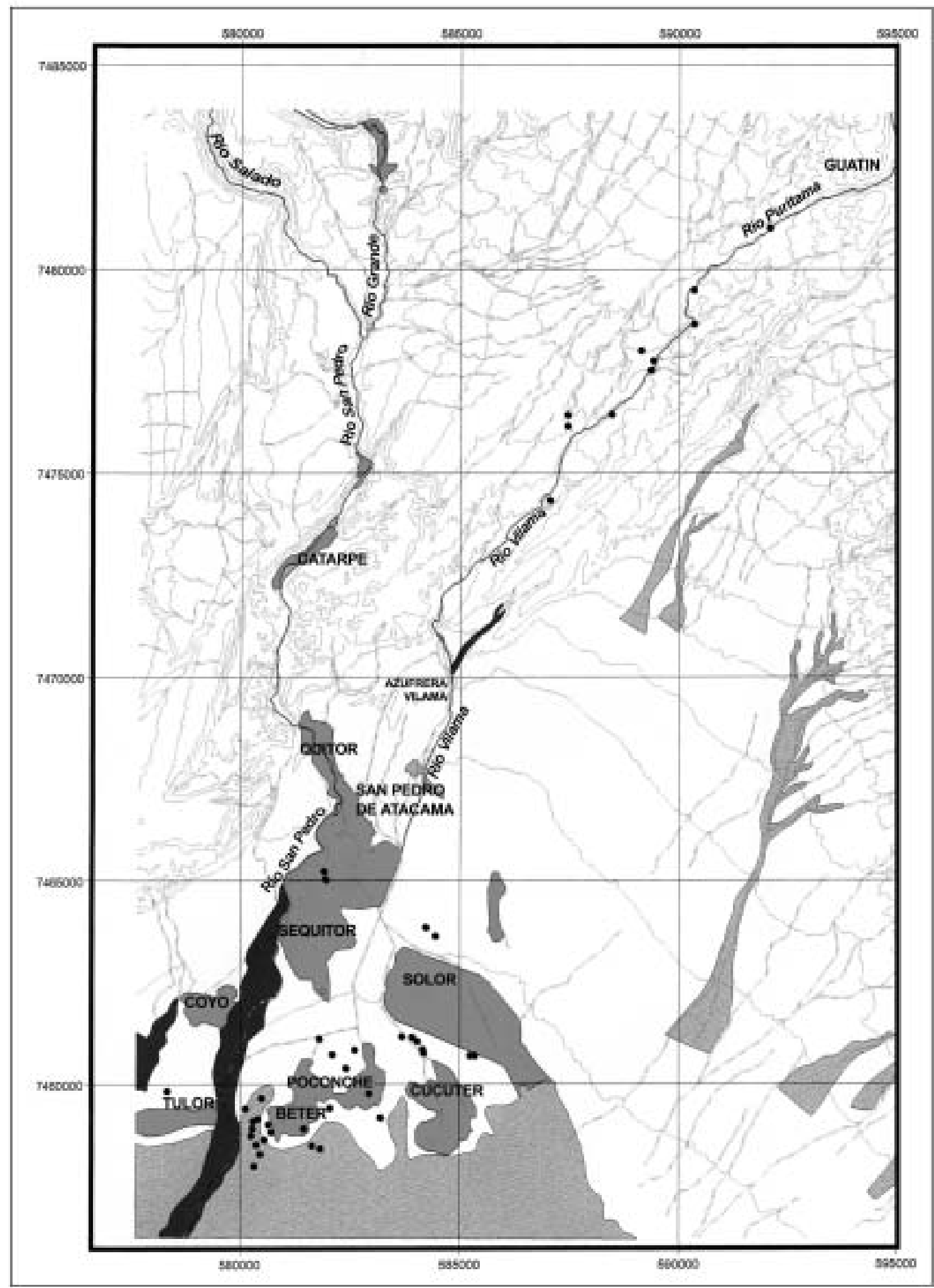

Figura 4. Ocupaciones correspondientes al Formativo Tardío. 


\begin{tabular}{|lcrrrr|r|}
\hline Categoría de sitios & \multicolumn{2}{c}{ Vilama } & \multicolumn{2}{c}{ Oasis } & \multicolumn{2}{c|}{ Total } \\
\hline Asentamiento Complejo Estructurado & 6 & $12.5 \%$ & 1 & $2.08 \%$ & 7 & $14.58 \%$ \\
Asentamiento Discreto Estructurado & 2 & $4.16 \%$ & 1 & $2.08 \%$ & 3 & $6.25 \%$ \\
Asentamiento Discreto No Estructurado & 0 & & 19 & $39.58 \%$ & 19 & $39.58 \%$ \\
Asentamiento Disperso No Estructurado & 0 & & 10 & $20.83 \%$ & 10 & $20.83 \%$ \\
Estancia & 1 & $2.08 \%$ & 0 & & 1 & $2.08 \%$ \\
Cantera-taller & 1 & $2.08 \%$ & 0 & & 1 & $2.08 \%$ \\
Estructura & 1 & $2.08 \%$ & 0 & & 1 & $2.08 \%$ \\
Fundición & 1 & $2.08 \%$ & 0 & & 1 & $2.08 \%$ \\
Cementerio & 0 & & 3 & $6.25 \%$ & 3 & $6.25 \%$ \\
Arte rupestre & 2 & $4.16 \%$ & 0 & & 2 & $4.16 \%$ \\
\hline Total & $\mathbf{1 2}$ & $\mathbf{2 5 \%}$ & $\mathbf{3 6}$ & $\mathbf{7 5 \%}$ & $\mathbf{4 8}$ & $\mathbf{1 0 0 \%}$ \\
\hline
\end{tabular}

Cuadro 9. Categorías de sitios durante el Formativo Tardío.

este momento, lo cual según señalan, pudo deberse a que otros asentamientos formativos previos se habrían destruido durante el proceso de erosión de las lluvias. Además, la exposición de la quebrada habría reactivado un intenso poblamiento a partir de 1760-1630 AP. Es probable que ello se deba a que desde la cota de Guatin ese sector de quebradas altas no sea integrado por los oasis, sino por comunidades pastoralistas, concibiéndose en San Pedro un manejo del territorio desde cotas que van de los $2370 \mathrm{~m} . \mathrm{snm}$ y los $3250 \mathrm{~m} . \mathrm{snm}$, más que de todos los pisos altitudinales del transecto, evidenciando un énfasis sobre todo agrícola y recolector.

En estos momentos surgen en los oasis varios asentamientos, ocupándose principalmente Beter, en el margen este del río San Pedro, aunque Tchaputchayna presenta una ocupación multicomponente de poblaciones locales, manifestando una continuidad desde el Formativo en adelante.

Todo lo anterior sugiere que los oasis se aprovechan agrícolamente y se explotan sus algarrobos, lo que en el contexto regional está documentado a partir de la alfarería SEQ que crea los primeros vasos para consumir chicha, en los oasis probablemente asociada a trabajos comunitarios agrícolas. Todo ello se vincula al modo de vida que están consolidando estas poblaciones, ya con pleno conocimiento de conservación de productos como maíz (pelado y seco, harina) y algarrobo (vainas, harina, chicha) que lleva al surgimiento de la producción excedentaria promoviendo el asentamien- to permanente en los oasis, lo que permite además, la explotación de las minas de cobre cercanas y su procesamiento, tal como lo indican las fundiciones cercanas al río San Pedro.

Posteriormente, según Llagostera y Costa (1999), el avance de las dunas determina que durante la Fase Quitor del Período Medio, la población se desplace a los sectores situados inmediatamente al norte, como Coyo, Beter, Sequitor, Quitor, Solcor y Solor, produciéndose en estos momentos la ocupación de prácticamente todos los oasis de San Pedro, con una mayor preferencia por los centrales, registrándose cementerios y sitios habitacionales. Nosotros registramos 50 ocupaciones del Período Medio que alcanzan un $12.85 \%$ (Cuadro 3). De éstas un 14\% se emplaza en el Vilama y un $86 \%$ lo hace en los oasis. Esto cambia un poco la situación propuesta por Llagostera y Costa (1999), ya que, si bien es elocuente un cambio en la ocupación del espacio, reduciéndose las ocupaciones en el Vilama e intensificándose en los oasis, esto se produce no sólo en los centrales sino también en los bajos (86\%), mostrando en este aprovechamiento una continuidad con el período anterior. Los asentamientos en la quebrada son prácticamente nulos $(8 \%)$, en cambio en los oasis aumentan a un $80 \%$.

En suma, la prospección aportó un importante número de nuevos asentamientos al registro de sitios de San Pedro de Atacama, categoría que estaba subrepresentada en relación a los cementerios. Al mismo tiempo, señala a la quebrada del Vilama como un sector que tuvo una ocupación 
significativa, y que precisamente, debido a su cercanía con los oasis, fue articulada en conjunto indicando que los patrones de asentamiento propuestos (Núñez 1995; Llagostera y Costa 1999) deben ser revaluados a la luz de estas nuevas evidencias.

\section{La secuencia formativa para los oasis de San Pedro}

Si bien el estudio previo de colecciones confirmó la propuesta tradicional para la secuencia formativa san pedrina (Berenguer et al. 1986; Núñez 1994; Tarragó 1989), así como la existencia de un momento temprano, ahora con los resultados de esta prospección como de los estudios de la arquitectura (Adán y Urbina 2005 Ms), alfarería (Uribe 2005, en prensa) y líticos (Carrasco $2005 \mathrm{Ms}, 2005 \mathrm{Ms}-\mathrm{a}$ ) vemos un panorama más complejo y diverso, puesto que tratamos con sociedades en un amplio rango temporal ocupando ecosistemas disímiles pero complementarios.

Estos resultados permiten enriquecer la fase inicial (1300-350 AC) con un total de 55 ocupaciones en el Vilama y los oasis bajos de San Pedro (Poconche, Cucuter y Tulor). La mayoría de éstas emplazada en el Vilama (principalmente en el segmento Ghatchi-Calar), y un porcentaje algo menor en los oasis, casi todas inaugurándose en este período, aunque un porcentaje menor sigue utilizando los sitios del Arcaico. En el ámbito de quebradas los asentamientos se emplazan en mesetas interfluviales de pendiente suave correspondientes a las primeras terrazas del río, con amplio dominio visual del entorno, abriéndose el lecho en estos sectores dando lugar a vegas, espacios aptos para el mantenimiento de camélidos. Los asentamientos se ubican cerca de vertientes ritualizadas con arte rupestre, y de lugares de aprovisionamiento de basalto, y conectados con otros asentamientos contemporáneos a través de quebradas y vías de circulación. De acuerdo a Adán y Urbina (2005 Ms) en ellos se comienza a desarrollar el patrón "recinto mayor y menores asociados en distribución radial" implicando un mayor costo energético y formal y conceptualmente vinculado al manejo de ganado por parte de comunidades iniciales de pastores. Su construcción excede los requerimientos necesarios para su uso como corrales, constituyendo un primer indicio de arquitectura pública, de probable uso ceremo- nial como cotidiano. Se trata de una tradición arquitectónica más antigua y que mejor se conoce en las quebradas aledañas al Salar de Atacama, mostrando una amplia ocupación espacial donde al parecer el río Vilama está tempranamente incorporado en el medio regional. Los materiales líticos fueron elaborados con una tecnología de láminas, aunque aparece de manera incipiente la tecnología sobre lascas, advirtiéndose un momento transicional. De acuerdo al hallazgo de puntas lanceoladas de andesita y perforadores, los sitios Ghatchi-2C (02-Vi-91) y Calar (02-Vi-117) en la cuenca del Vilama y 02-Po-18 en Poconche, y 02Be-02 en Beter tendrían una ocupación arcaica/ formativa temprana (Carrasco $2005 \mathrm{Ms}$ ). Por otra parte, en los oasis los asentamientos construidos con materiales perecederos se emplazan casi exclusivamente en Beter, Cucuter y Poconche, y en menor proporción en Tulor, lo que sugiere el aprovechamiento de los desaguies de los ríos Vilama y San Pedro para el desarrollo de actividades hortícolas y la recolección estacional de los frutos de chañares y algarrobos. Se registran pocos instrumentos cortantes y raspadores, y sí conas, manos y palas líticas que, aunque escasas, indican actividades hortícolas y una distancia del procesamiento de carne. Surge el primer cementerio de los oasis con contextos con adornos, como cuentas de collar de mineral de cobre y tembetás. En los asentamientos destacan los perforadores. Por otra parte, los tipos cerámicos en los oasis, como Poconche, Cucuter y ciertos sectores de Tchaputchayna manifiestan un vínculo con los sitios tempranos de las quebradas, señalando una etapa inicial dentro del Formativo análoga a las quebradas (Uribe 2005, en prensa). Todo ello es coherente con la cercana proporción de sitios en quebrada y oasis que estaría indicando una utilización complementaria de esos territorios. Tal complementariedad se reafirmaría en el surgimiento de cierto nivel de arquitectura pública en Ghatchi, la que generaría estrategias de significación social y congregación comunitaria, y en la presencia del primer cementerio de los oasis, en Poconche. Por otra parte, el tipo LCA en cierta medida contemporáneo a LMS tendría raíces en la cuenca del Loa, más que en San Pedro, siendo ambos evidencias foráneas a los oasis, sugiriendo un origen externo y ubicable preliminarmente en el Loa, la puna atacameña y la vertiente oriental circumpuneña, confirmando que los momentos tempranos, principalmente en la cuenca del 
Vilama, se vinculan con las tierras altas y orientales de la vertiente oriental circumpuneña (Uribe 2005, en prensa). Con ello, los grupos del sector Ghatchi-Calar están tempranamente articulando un territorio bastante amplio posicionándose con respecto a los recursos locales como a las vías de circulación, movilidad y acceso a otros espacios, como la cuenca del río Salado, la Puna y, por supuesto, principalmente, los oasis de San Pedro.

En un segundo momento, correspondiente al Formativo Medio, entre los 350 AC-100 DC, y analogable a la Fase Toconao, ya ocurrirían ocupaciones permanentes en aldeas, como Tulor-1 con cementerios como Larache Acequia y Sequitor Alambrado-Acequia. Las evidencias de prácticas agrícolas resultaron evidentes, así como las de recolección, mientras aparece con claridad una serie de indicadores culturales de relaciones con el Pacífico y el N.O.A. Las ocupaciones disminuyen en la quebrada de Vilama, registrándose la mayoría de los sitios en los oasis bajos, donde el sistema de asentamiento disperso conformado por lo menos por 26 sitios de la fase anterior originan aldeas aglutinadas, como Tulor1 y Tulor-4 y dos nuevos cementerios, uno de los cuales tiene contextos destacables. La distribución de los sitios indica que se ocupan un poco más los oasis centrales como Yaye y Larache. Por su parte, en el Vilama siguen utilizándose pocos sitios del segmento Ghatchi-Calar, especialmente Calar. Lo anterior, plantea para estos momentos la existencia de prácticas económicas complementarias de recolección y agricultura de campos inundados hacia los oasis bajos, junto a prácticas de pastoreo hacia el sector de Ghatchi-Calar. La aparición de los vasos SEQ probablemente asociados al consumo de chicha (de algarrobo?) señalan el fortalecimiento de prácticas agrícolas en los oasis. A esta situación se suma la emergente especialización productiva en bienes "de prestigio", que requiere de la articulación y operación de redes de obtención de materias primas, como también de circuitos de circulación, a corta distancia (Calar-Loma Negra) y a larga distancia (N.O.A., Pacífico). La dispersión de la cerámica SEQ en la vertiente occidental de la circumpuna es una prueba de ello, pudiendo probablemente asociarse a otro tipo de situaciones comunitarias localmente establecidas. La arquitectura de Calar y Ghatchi-1A y su patrón de recintos circulares en torno a patios centrales posee referentes a nivel circumpuneño, principal- mente en las quebradas altas y espacios cercanos al Altiplano Meridional, extendiéndose hasta sectores orientales de valles y sierras en el N.O.A., constituyendo una tradición arquitectónica ancestral que tiene una gran dispersión regional, indicando que estos grupos están articulando un territorio bastante amplio. En San Pedro, el patrón arquitectónico de Tulor-1 con un importante manejo del barro es particular de los oasis. La variabilidad de sus estructuras enfatiza los espacios de almacenaje, residencia y circulación, la que requirió secuencialmente de un complejo sistema de accesos, pasillos y ambientes vestibulares alrededor de las estructuras circulares, mostrando una clara intención por segmentar los espacios hacia los momentos de mayor crecimiento e intensidad ocupacional de la aldea, lo que apoya la idea de Llagostera y colaboradores (1984) respecto a que la fuerte readecuación funcional de Tulor se relaciona con un proceso de jerarquización en el sistema de asentamiento. En cuanto a la alfarería, es a partir de LMS-B con pastas graníticas, que el estilo tecnológico deriva en la tradición atacameña de alfarería monocroma (tipos TOC, SEQ y LRA). Esta paulatina integración que se va observando en el sistema de asentamiento, se vincularía a la autonomía del sistema económico principalmente recolector y agrícola y en menor grado pastoralista, promoviendo una mayor estabilidad y complejidad social.

Finalmente, el tercer momento del Formativo (100-500 DC) transita hacia el Período Medio con un crecimiento poblacional, ayudado por una mayor estabilidad económica, junto a una creciente complejidad social. Está representado por 48 ocupaciones de las cuales la mayoría se emplazó en los oasis inaugurándose varias en este momento, y donde se crean dos cementerios más, y fundiciones de cobre. La ocupación de los espacios quebradeños disminuye notablemente, especialmente los asentamientos, permaneciendo algunos pocos en el segmento Ghatchi-Calar, donde esta aldea integra el primer cementerio de la quebrada (el que presenta continuidad con el de Poconche), cuando la ocupación de este ámbito disminuye, pero al mismo tiempo hay evidencias de prácticas agrícolas cercanas al lecho, indicando cierta propiedad por parte de los oasis sobre la quebrada media. En estos momentos la población se concentra en San Pedro, con más sitios, con abundante y diversa cerámica. Se abandona el asentamiento de Tulor-1, ocupándose sobre todo Beter, 
en el margen este del río San Pedro. Los oasis se aprovechan agrícolamente y se explotan sus algarrobos. Todo ello en asociación al modo de vida que están consolidando estas poblaciones, ya con pleno conocimiento de conservación de productos, como maíz y algarrobo cuya producción excedentaria promueve el asentamiento permanente en los oasis, lo que permite además la explotación de las minas de cobre cercanas y su procesamiento, tal como lo indican las fundiciones cercanas al río San Pedro. Ello en el contexto de sociedades que requieren ya de la circulación de bienes de prestigio para la mantención de relaciones sociales, políticas y económicas.

\section{Conclusiones}

La prospección aportó un importante número de nuevos asentamientos al registro de sitios de San Pedro de Atacama, categoría que estaba subrepresentada en relación a los cementerios. Al mismo tiempo, indicó a la quebrada del Vilama como un sector que tuvo una ocupación significativa. Precisamente debido a su cercanía, ambas zonas debieron estar relacionadas indicando que los patrones de asentamiento propuestos para los oasis (Núñez 1995; Llagostera y Costa 1999) deben ser revaluados a la luz de estas nuevas evidencias.

En particular para el Período Formativo, fue elocuente la mayor ocupación de los oasis en relación a la quebrada. Este ámbito durante el Formativo Temprano es levemente más utilizado que el primero; durante el Formativo Medio la proporción es un poco más favorable a los oasis; y por último en el Formativo Tardío hay una clara desproporción entre ambas zonas, siendo mucho más ocupados los oasis.

Con ello, nuestros resultados contrastan con aquellos de Llagostera y Costa (1999), los que señalaban que el asentamiento humano en los oasis aparece muy relacionado con el ingreso del maíz, emplazándose los sitios al pie de puna, cerca de la desembocadura de ríos, en el borde suroeste de los oasis de San Pedro, en Tulor. Según nuestro registro, el asentamiento humano precede al ingreso del maíz, relacionándose más bien con prácticas de recolección que deben haber sido importantes para observar en los meses de verano -en los cuales se realiza la recolección de chañar y de algarrobo- las condiciones apropiadas para las primeras prácticas hortícolas.

El número de sitios registrados tanto en la quebrada como en los oasis resultó ser significativo, y en estos últimos no sólo en Tulor, sino además en Cucuter, Poconche y Beter. Además, se observó que el período cuenta con una mayoría de ocupaciones monocomponentes (en el Vilama y en los oasis), lo que, junto a una mayor diversidad de sitios, por una parte muestra un cambio en el modo de vida, en las concepciones sobre el manejo del territorio y sus recursos, y por otra, indica una situación de complementariedad entre ambas zonas, la que fue cambiando desde el momento temprano del período al tardío del mismo.

La articulación de los sistemas de quebrada y oasis fue más recurrente en los momentos tempranos y medios del período, señalando grupos posiblemente más pequeños, menos permanentes o más móviles, mientras que hacia finales del Formativo se concentran en los oasis, lo que interpretamos como el tránsito de una economía complementaria basada en prácticas de caza y pastoreo y recolección y horticultura a otra sustentada en recolección y agricultura de maíz y en menor medida pastoreo, al contrario de lo que ocurriría en el Loa Superior y en el sur del Salar. De acuerdo a los datos que hemos obtenido, el manejo del territorio a partir del Formativo en la zona de estudio incluyó a los oasis y quebradas bajas aledañas entre los 2370 y 3250 m.snm. De esta manera, el manejo de camélidos se habría realizado en las quebradas altas y no en el pie de puna, lo que explica que en épocas posteriores los indicadores de caravaneo no se encuentren en los oasis, sino en otros lugares ancestralmente relacionados al pastoralismo, que no a la agricultura ni a la recolección de frutos de algarrobo.

De acuerdo a la mayor cantidad de sitios en el oasis hacia el Formativo Medio y Tardío se aprecia un considerable crecimiento y estabilidad de la población, concentrándose en los oasis hasta formar aldeas (Llagostera et al. 1984), lo cual habría implicado durante el Formativo Tardío un particular control sobre un territorio acotado a los ámbitos de oasis y quebradas bajas, constituyéndose San Pedro en un centro poblacional, compuesto de varias comunidades agrícolas, y la quebrada aledaña en un sector complementario apto para el 
mantenimiento menor de ganado, obtención de materias primas, utilización de los sectores abiertos para las prácticas agrícolas, y tránsito.

En efecto, la contemporaneidad de algunos sitios, como Tulor y Calar, con algunos momentos de Tulan y Puripica sugiere que existirían economías diferenciadas, teniendo estos últimos un predominio de las prácticas de caza y pastoreo. Tal escenario, como plantean Adán y Urbina (2005 Ms), permite preguntarnos si se trata de un sistema de asentamiento articulado por grupos de una misma tradición cultural, vale decir, comunidades instaladas de manera más permanente en los oasis, ocupando periódicamente ecosistemas de quebradas medias y altas o, por el contrario, y como parece indicar preliminarmente el registro arqueológico, es expresión de dos tradiciones culturales distin- tas, una quebradeña, cazadora y pastoralista con un fuerte remanente de las sociedades arcaicas, y otra de oasis, recolectora y agrícola que comienza a exhibir y desarrollar las innovaciones tecnológicas del período. Ello plantearía una interesante diversidad cultural para el Formativo, documentándose la dicotomía espacial que configurará la identidad cultural de estos territorios.

Agradecimientos A todos los colegas y amigos que han colaborado hasta esta etapa de la investigación: Mauricio Uribe, Carlos Carrasco, Leonor Adán, Simón Urbina, Josefina González, Alejandra Vidal, Ulises Cárdenas, Danisa Catalán, Patricia Ayala, Jimena Cruz, Nahuel Wietzerbin y Steffen Welsh. También a Nuriluz Hermosilla, por facilitarnos los materiales recuperados por ella del sitio Yaye Corral de Toros.

\section{REFERENCIAS CITADAS}

ADAN, L. y S. URBINA, 2005 Ms. Arquitectura formativa en los oasis y quebradas de San Pedro de Atacama: Análisis de los sitios Tulor-1, Calar y Ghatchi-2C. Anexo 9 de Informe $2^{\circ}$ Año Proyecto FONDECYT 1030931.

AGÜERO, C., L. NUÑEZ, M. URIBE, C. CARRASCO, A. VIDAL, J. GONZALEZ, D. CATALAN y U. CARDENAS, 2004 Ms. Registro y cronología del Período Formativo en los oasis de San Pedro de Atacama. Informe $1^{\circ}$ Año Proyecto FONDECYT 1030931, Santiago.

BARON, A. M., 1986. Tulor: Posibilidades y limitaciones de un ecosistema. Chungara 16-17: 279-288.

BERENGUER, J., A. DEZA, A. ROMAN y A. LLAGOSTERA, 1986. La secuencia de Myriam Tarragó para San Pedro de Atacama: Un test por termoluminiscencia. Revista Chilena de Antropología 5: 17-54.

CARRASCO, C., 2005 Ms. Uso y variabilidad de materias primas líticas en la cuenca del Vilama y oasis bajos de San Pedro de Atacama. Anexo 8 de Informe $2^{\circ}$ Año Proyecto FONDECYT 1030931.

2005 Ms-a. Aproximación al comportamiento histórico cultural de la materialidad lítica durante el Período Formativo en San Pedro de Atacama.

HERMOSILLA, N., R. SANCHEZ y M. URIBE, 2003 Ms. Proyecto Hotel en ayllu de Yaye, San Pedro de Atacama, II Región. Ampliación de Línea Base sitio "Corral de Toros”. Estudio preparado para AMBAR S. A.

LE PAIGE, G., 1957-58. Antiguas culturas atacameñas en la cordillera chilena. Anales de la Universidad Católica de Valparaíso 4-5: 15-144.
_ 1963. Ghatchi y su zona. Revista Universitaria (Universidad Católica de Chile), Año XLVIII, pp. 177-193.

_-1963a. Continuidad o discontinuidad de la Cultura Atacameña. Anales de la Universidad del Norte 2: 7- 25.

_ 1964. El precerámico en la cordillera atacameña y los cementerios del Período Agroalfarero de San Pedro de Atacama. Anales de la Universidad del Norte 3.

1970. Industrias líticas de San Pedro de Atacama. Ediciones Orbe y Universidad del Norte, Santiago.

—_1974. El yacimiento de Tchaputchayna. Estudios Atacameños 2: 59-74.

-1974a. Informes de trabajo. Estudios Atacameños 2: 101-104.

LLAGOSTERA, A., 1988. Informe sobre investigaciones arqueológicas en Calar. Boletín de la Sociedad Chilena de Arqueología 8: 1.

-1996. San Pedro de Atacama: Nodo de complementariedad reticular. En La integración surandina cinco siglos después, X. Albó et al. (Comps.), Universidad Católica del Norte y centro de Estudios Regionales Andinos Bartolomé de las Casas, pp. 17-42. Estudios y Debates Regionales Andinos 91, Cuzco.

LlaGosterA, A. y A. COSTA, 1999. Patrones de asentamiento en la época agroalfarera de San Pedro de Atacama (norte de Chile). Estudios Atacameños 17: 175-206. 
LLAGOSTERA, A., A. M. BARON y L. BRAVO, 1984. Investigaciones Arqueológicas en Tulor-1. Estudios Atacameños 7: 133-151.

NUÑEZ, L., 1976. Registro regional de fechas rediocarbónicas del norte de Chile. Estudios Atacameños 4: 74-123.

-1992. Cultura y conflicto en los oasis de San Pedro de Atacama. Editorial Universitaria, Santiago.

- 1994. Emergencia de complejidad y arquitectura jerarquizada en la Puna de Atacama: Las evidencias del sitio Tulan-54. Actas del Taller "De Costa a Selva: Producción e intercambio entre los pueblos agroalfareros de los Andes Centro Sur" (1992). Instituto Interdisciplinario de Tilcara, San Salvador de Jujuy.

-1995. Evolución de la ocupación y organización del espacio atacameño. En Agua, ocupación del espacio y economía campesina en la región atacameña. Aspectos dinámicos, L. Pourrut y L. Núñez (Eds.), pp. 18-60. Universidad Católica del Norte, Antofagasta.

NUÑEZ, L. y C. AGÜERO, 2003. Ms. Línea Base Arqueológica. Acueducto Pampa Puno al Tranque San Pedro. Estudio preparado para CODELCO, Chuquicamata.

NUÑEZ, L., M. GROSJEAN e I. CARTAJENA, 1999. Un ecorrefugio oportunístico en la Puna de Atacama durante eventos áridos del Holoceno Medio. Estudios Atacameños 17: $125-174$
ORELLANA, M., 1988-89. Los tipos alfareros tempranos de Calar y su contexto aldeano. Paleoetnológica 5: 73-86.

1990. Calar: Una aldea temprana del norte de Chile. Creces 3 (11): 23-28.

SERRACINO, G., 1976. Tulor-4: Cuatro pozos de sondeo. Estudios Atacameños 4: 24-31.

SERRACINO, G. y R. STEHBERG, 1974. Las estructuras de piedra de Ghatchi (San Pedro de Atacama). Norte Grande 1 (2): 185-210.

STOVEL, E., 1997. Habitational analysis and cultural contact at Coyo Aldea, Northern Chile. The surface deposits. Tesis para obtener el grado de Master of Arts in Anthropology, Graduate School of the State University of New York at Binghamton.

TARRAGO, M., 1989. Contribución al conocimiento arqueológico de las poblaciones de los oasis de San Pedro de Atacama en relación con los otros pueblos puneños, en especial el sector septentrional del valle Calchaquí. Tesis para optar al Título de Doctor en Historia, Especialidad Antropología. Universidad Nacional de Rosario, Facultad de Humanidades y Artes, Rosario.

URIBE, M., 2005. Sobre cerámica, su origen y complejidad social en los Andes del Desierto de Atacama, norte de Chile. En Esferas de interacción prehispánicas y fronteras nacionales modernas. Los Andes Sur Centrales, $\mathrm{H}$. Lechtman (Ed.). IEP, Lima. En prensa. 
CAROLINA AGÜERO P

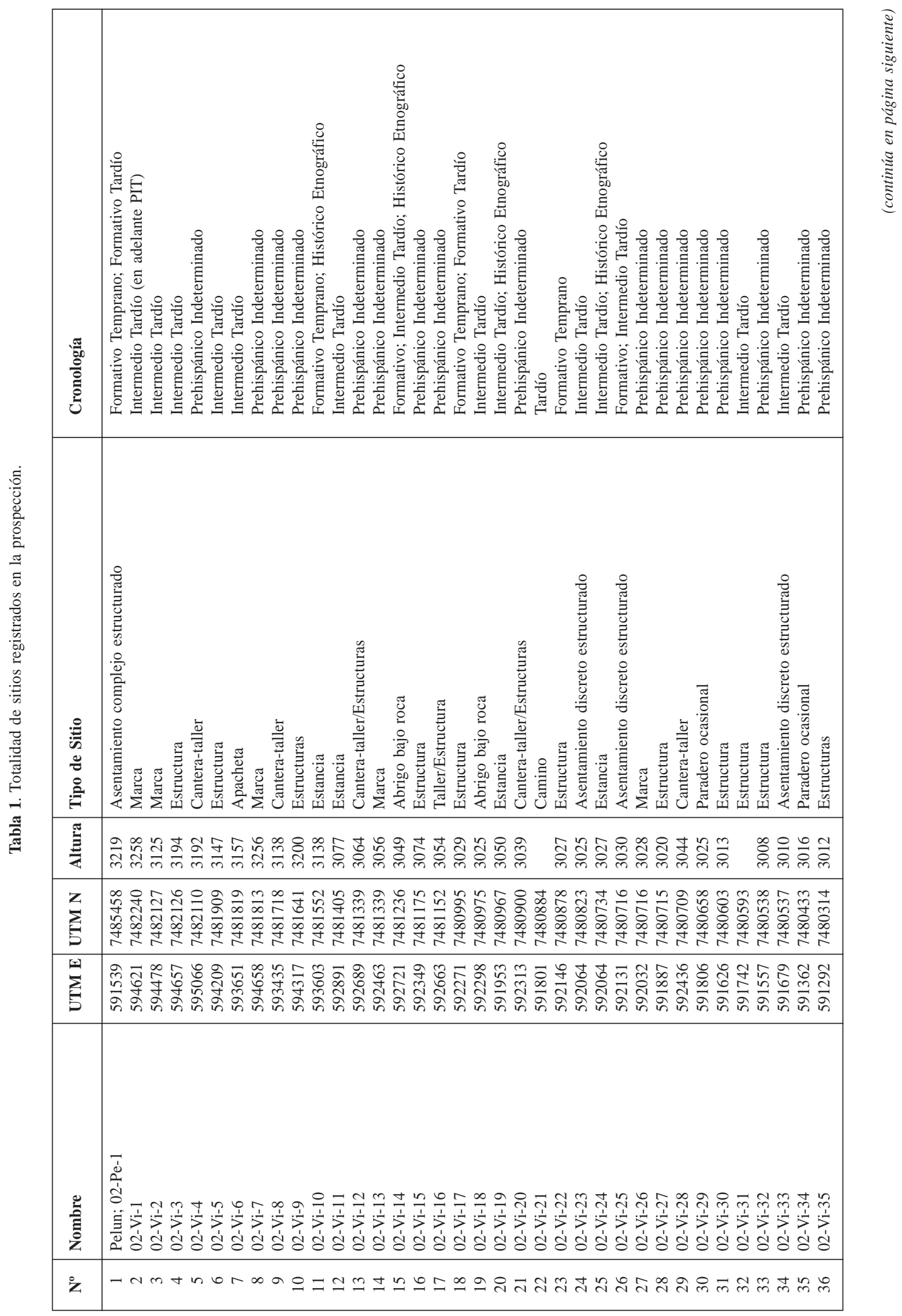


APROXIMACION AL ASENTAMIENTO HUMANO TEMPRANO..

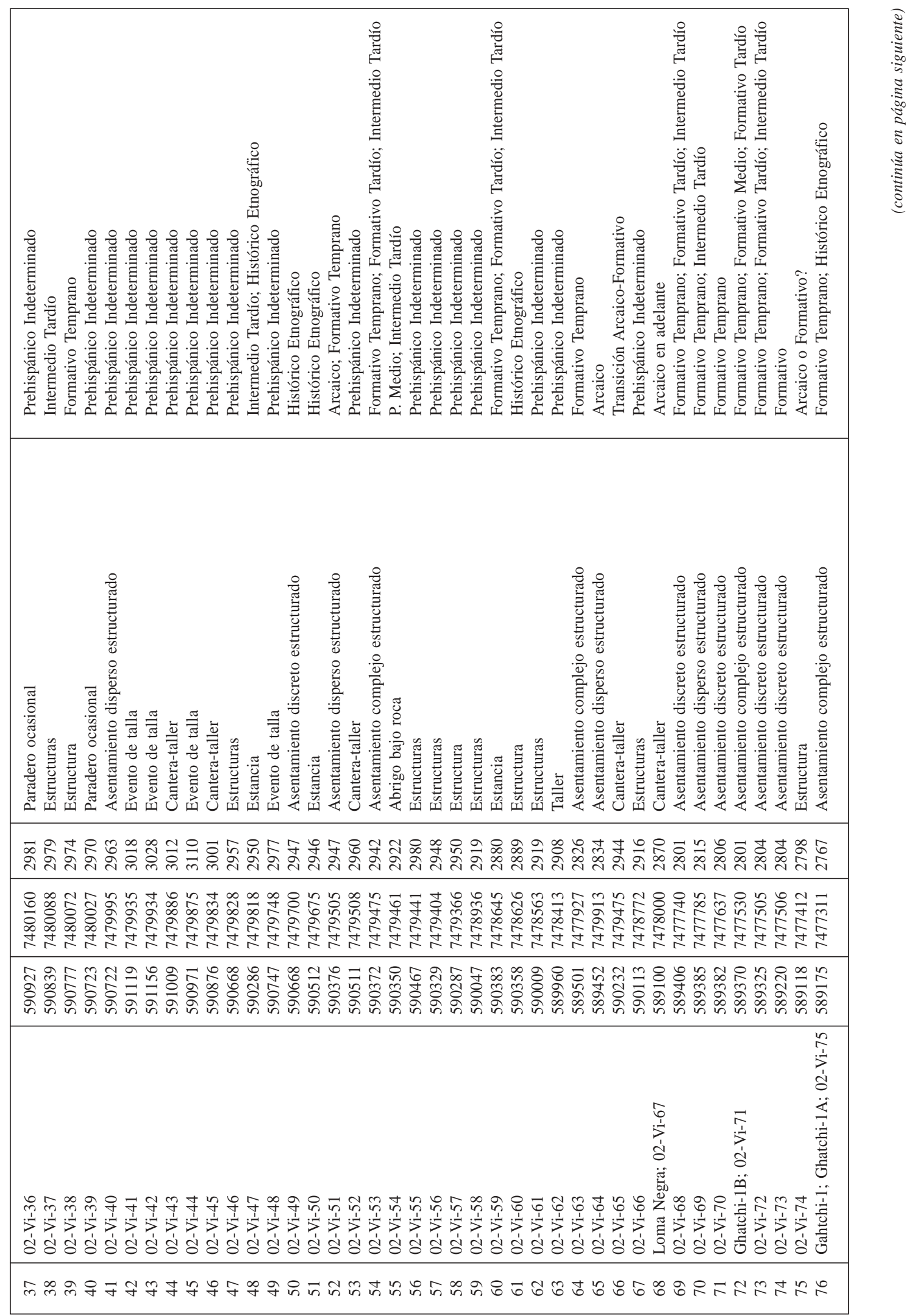




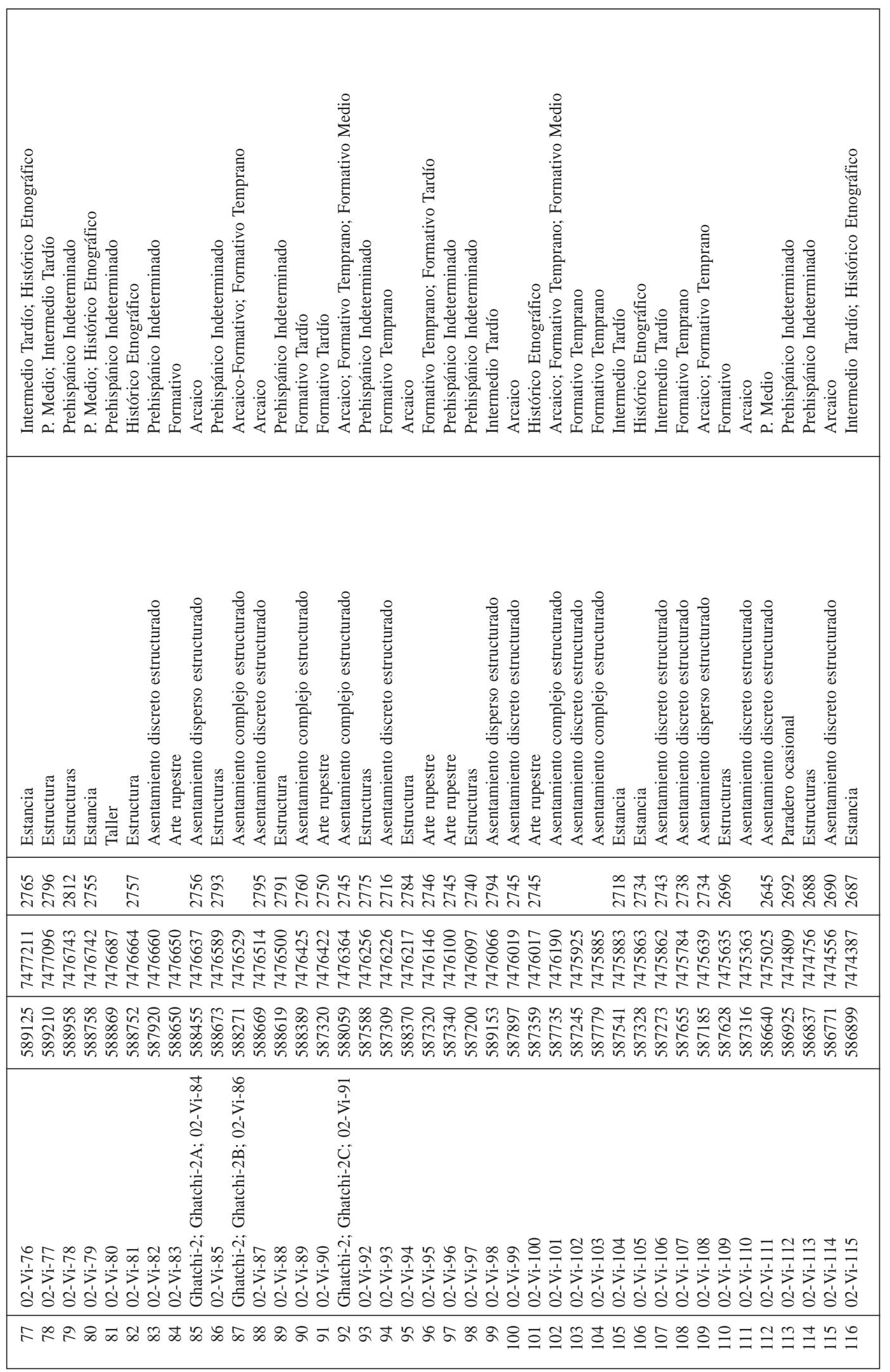


APROXIMACION AL ASENTAMIENTO HUMANO TEMPRANO..

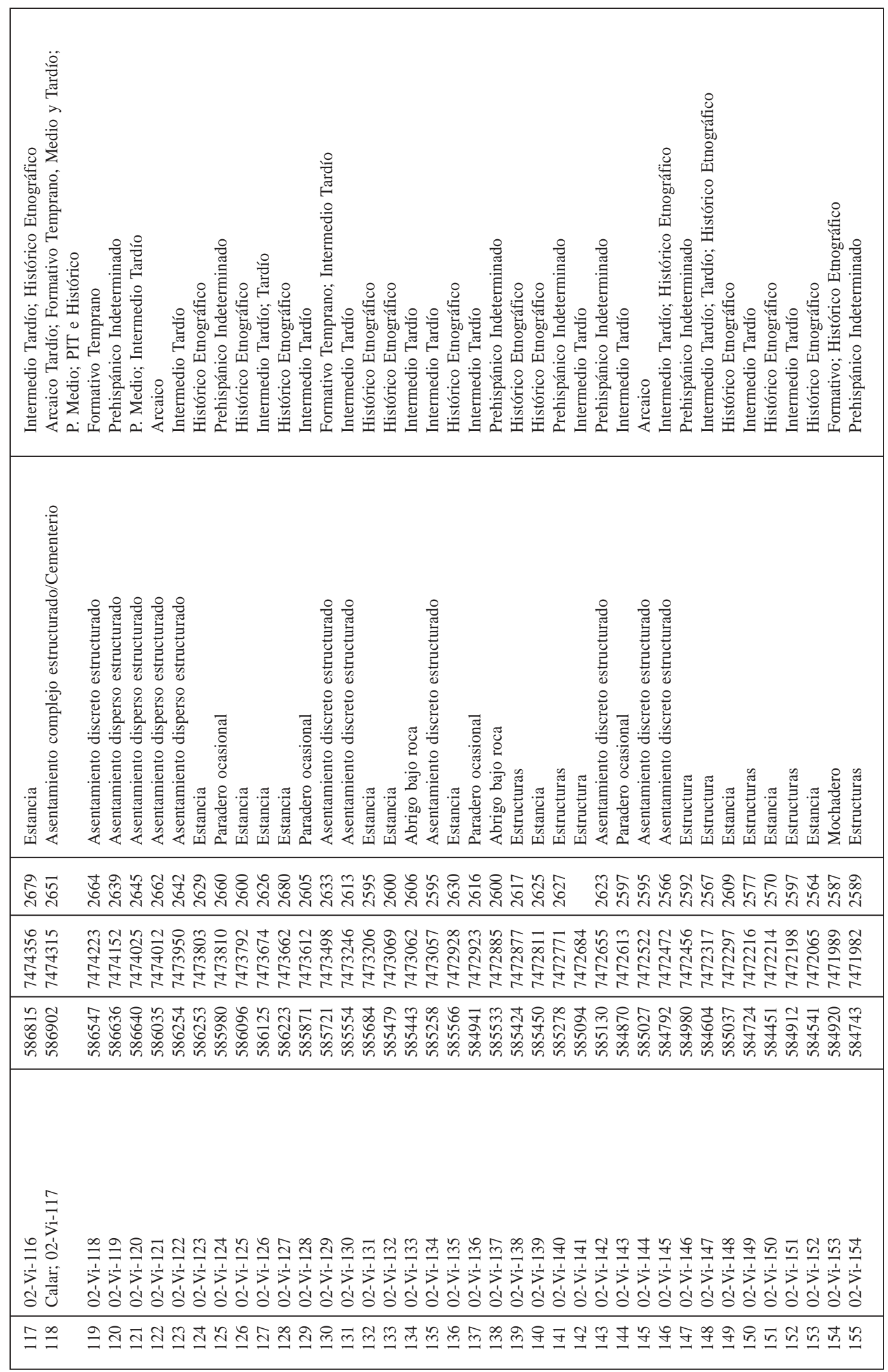




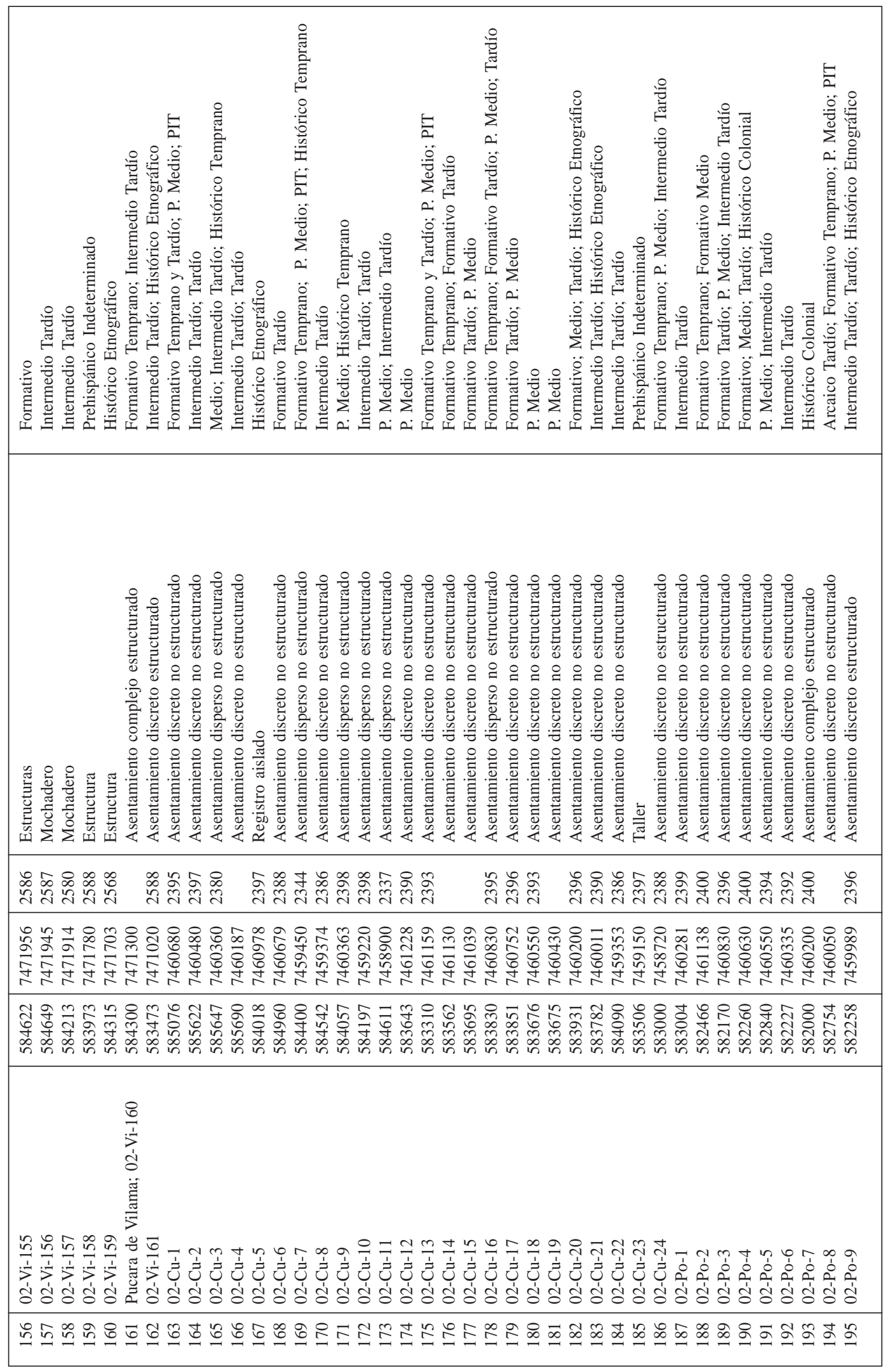


APROXIMACION AL ASENTAMIENTO HUMANO TEMPRANO..

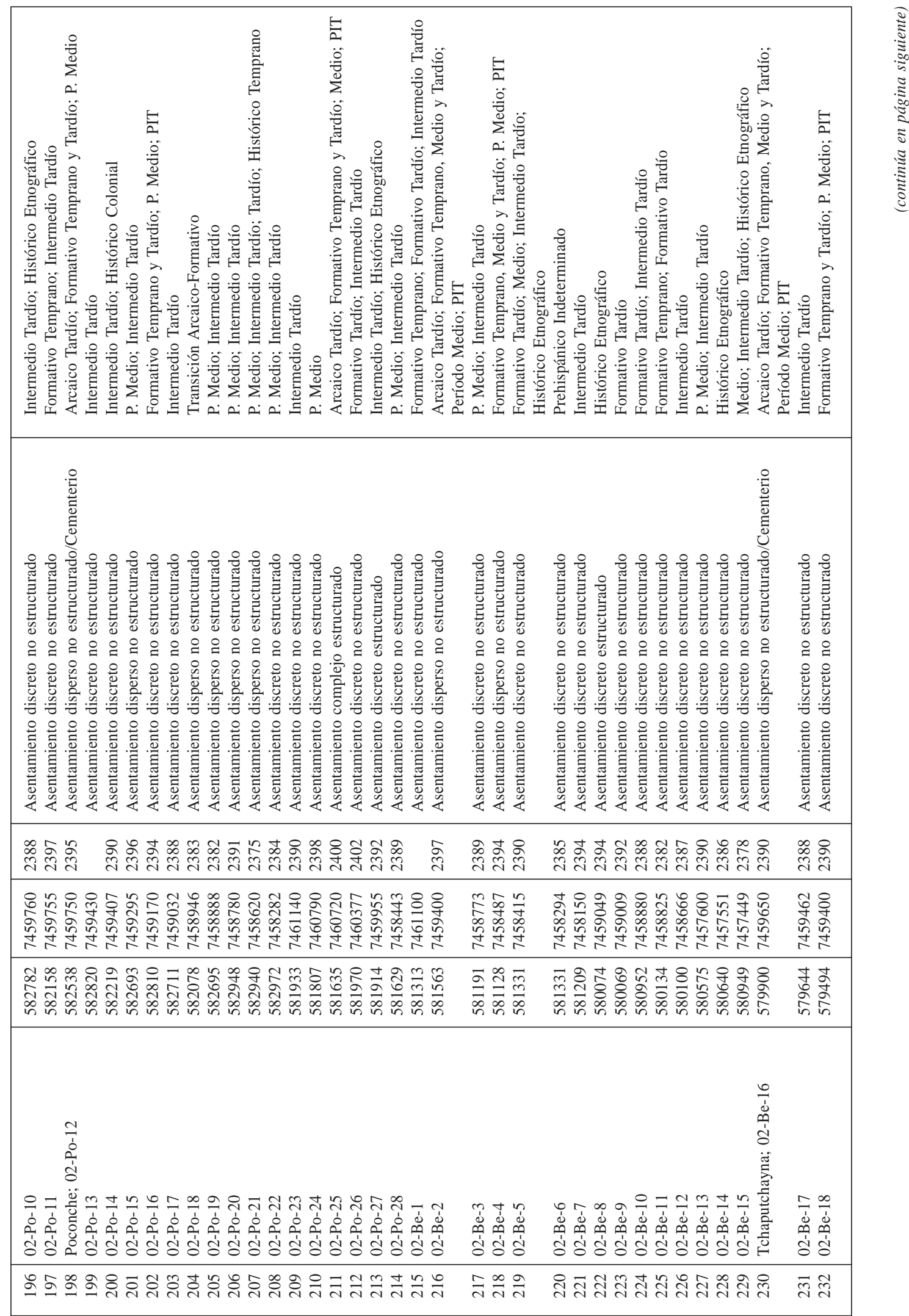




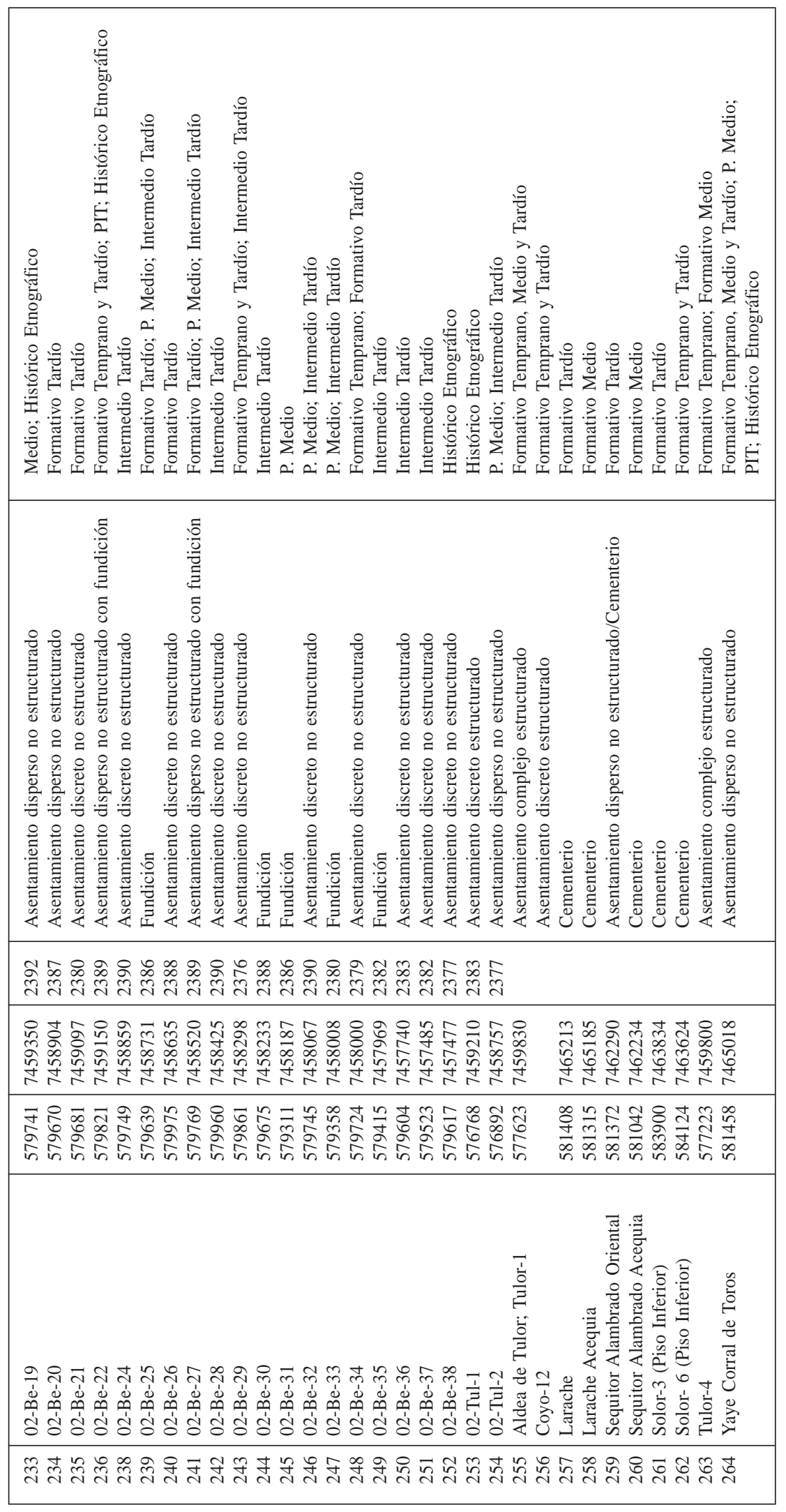

